\title{
Reliable Aerial Thermography for Energy Conservation
}

John R. Jack and Robert L. Bowman

National Aeronautics and Space Administration Lewis Research Center

August 1981

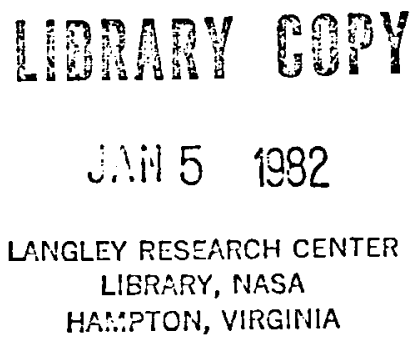

Prepared for

U.S. DEPARTMENT OF ENERGY

Conservation and Renewable Energy Division of Building and Community Systems 


\section{NOTICE}

This report was prepared to document work sponsored by the United States Government. Neither the United States nor its agent, the United States Department of Energy, nor any Federal employees, nor any of their contractors. subcontractors or their employees, makes any warranty, express or implied, or assumes any legal liability or responsibility for the accuracy, completeness, or usefulness of any information. apparatus, product or process disclosed, or represents that its use would not infringe privately owned rights 


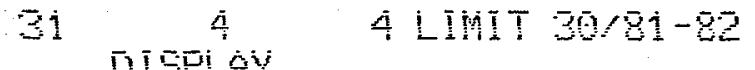

$$
\begin{aligned}
& 32 \text { का } \\
& 1 \text { PNACA-TM-81765 }
\end{aligned}
$$

\section{DXIII: PEEYIOUS OUTPUT COMEIETED}

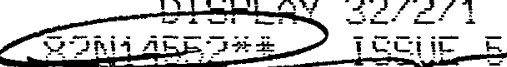
DOE HÂC $20270-15-82$

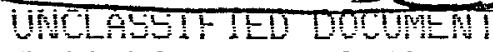

PACE EST CATEGOEV $\frac{\pi}{3}$ QPT UTIL: Pel iable aerial thermograny for energy conservation

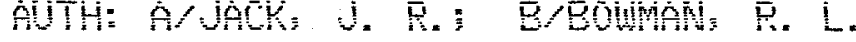

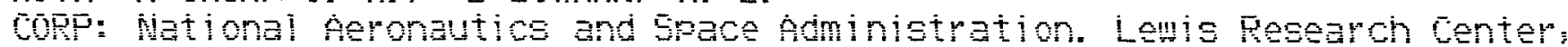

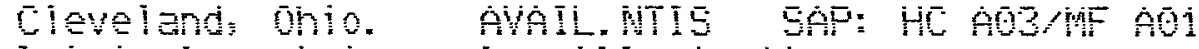
original contains color iliustrations

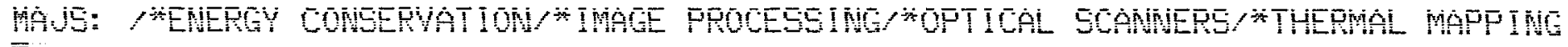
를 


$$
1
$$


DOE/NASA/20270-1

NASA TM-81766

\section{Reliable Aerial Thermography for Energy Conservation}

John R. Jack and Robert L. Bowman

National Aeronautics and Space Administration

Lewis Research Center

Cleveland, Ohio 44135

August 1981

Work performed for

U.S. DEPARTMENT OF ENERGY

Conservation and Renewable Energy

Division of Building and Community Systems

Washington, D.C. 20545

Under Interagency Agreement DE-Al01-79CS20270 
SUMMARY

Extensive energy conservation programs are being implemented throughout the country because prime energy sources are dwindling and as a result energy costs are skyrocketing. One method currently being used on a large scale to promote energy conservation is the aerial thermography survey. Its concept and its use for locating sources of energy losses and wasteful energy management practices are quite straightforward and very effective when the thermographs are obtained under proper conditions and have good discrimination, that is, structures and energy losses are easily and simply discerned in the imagery.

However, over the past several years, thermography has been acquired with possible ambiguities that have caused confusion in the interpretation of the imagery. In an attempt to eliminate ambiguities, an operational map is presented for clear-sky conditions. This map outlines the key environmental conditions conducive to obtaining reliable aerial thermography. The map is developed from defined visual and heat loss discrimination criteria that are then quantized based on flat-roof heat transfer calculations. Data from previous NASA and independent contractor thermography are discussed with reference to the operational map. Appendixes discuss uncertainties involved in selecting values for the parameters used in the analysis. A suggested specification for obtaining an aerial thermography survey is also presented.

\section{INTRODUCTION}

The NASA Lewis Research Center has been using aerial thermography for several years to help NASA implement its agency-wide energy conservation program. All the NASA field centers have been surveyed with very good results. Typical energy losses easily detected were those through roofs and central heating system distribution lines, building ventilating losses, and losses associated with electrically heated steps and sidewalks (refs. 1 to 3 ). The aerial thermography proved to be very cost effective, with a firstyear estimated net savings of $\$ 386000$.

The success of the NASA in-house energy conservation effort using aerial thermography led to several small ( 3 to 5 square miles) city demonstration projects principally associated with the Department of Housing and Urban Development (HUD) winterization program. These demonstrations were conducted through the NASA Technology Applications Transfer Office with several purposes: implementation of the National Energy Policy of 1977, stimulation of state legislative action for state-wide energy conservation programs, establishment of priorities in HUD's residential winterization program, and finally, demonstration of the utility of the technology and transfer of it to the user community. By so doing, energy conservation is promoted and a market is created for private contractors capable of doing aerial infrared surveys (refs. 4 and 5 ). 
In the course of doing the NASA demonstrations and during other demonstrations performed by private contractors, aerial thermography was obtained that could not be easily interpreted by the user community and was therefore not effective in promoting energy conservation. On many occasions thermography was obtained and exhibited wherein buildings blended into the background, preventing good visual and temperature discrimination (ref.6). Al though energy losses from roofs were known to exist, they could not be detected easily from the imagery. Evidently the energy losses were highly masked by the effect of environmental conditions on the heat transfer mechanisms. For example, at a fixed wind velocity, a low ambient air temperature yields thermographs that can clearly identify and discriminate energy losses but that do not clearly define building outlines. Acquisition at a slightly higher air temperature produces thermographs that easily discriminate both structures and energy losses. Yet, at still a slightly higher air temperature, the imagery obtained permits identification of buildings but not energy losses. As a result the interested user community began to question the credibility of thermography. A key question was consistently being asked: If aerial thermography is to be used in comprehensive surveys, what is required to insure reliable thermography? An analytical study was begun to attempt to answer this question.

This report presents typical thermal imagery illustrating some of the environmental effects that can be encountered and presents an analytical model that describes the energy loss mechanisms for clear-sky conditions in terms of the controlling parameters. The analytical results are discussed, and environmental criteria are suggested for obtaining thermography with good visual and heat loss discrimination. These suggestions are incorporated into an operational map developed to avoid ambiguities in the thermographs. Finally the data from past NASA and independent contractor thermographs are interpreted in the context of the operational map.

QUALITATIVE EFFECTS OF ENVIRONMENTAL CONDITIONS ON AERIAL THERMOGRAPHY

Imagery is presented to illustrate the effects of surface winds and ambient air temperatures encountered in thermography surveys so that the user will be aware of and become familiar with these qualitative effects. In each case the imagery has been processed to exhibit the best visual and heat loss discrimination possible under the conditions of the thermography survey.

The effect of surface wind on thermal imagery is illustrated in figure 1. The overall picture is of an elementary school complex surrounded by residential housing with a church and a small shopping center. The main difference between figures $1(a)$ and (b) is surface wind. In general for the high surface wind (fig. 1(a)) the houses, church, shopping center, and elementary school are not as clearly defined as for the low surface wind. This occurs because high surface wind tends to bring roof surface temperatures closer to the background temperature and thus greatly reduces temperature differences. Heat losses from some of the houses are more easily seen in the low wind case. As a result of this qualitative look at the surface wind effect it could be concluded, as it has been in the past, that surface winds should be as low as possible for aerial thermography. The quantitative effects of surface winds on flat roofs are presented and discussed in detail in a subsequent section. 
The effect of ambient temperature is illustrated in figures 2 . The outlined view is of a one- by two-block area of residential houses and small businesses. Although neither image ( $\mathrm{fig} .2(\mathrm{a})$ or $(\mathrm{b})$ ) is considered very good, the discrimination of structures is considerably enhanced at the lower ambient temperature because more heat is lost and more temperature contrast is obtained between roof tops and the background. Thus it could be concluded, as it has been in the past, that with all other environmental conditions constant the ambient temperature should be as low as possible.

ANALYTICAL MODEL

The mathematical model used for predicting energy losses from building roofs has several simplifying assumptions. The roof surface is assumed to be horizontal with radiation impinging on it only from the sky, and the heat flow from inside the structure is assumed to be one dimensional and quasisteady. A flat roof with zero view factors to various sources of ground radiation was chosen because it is typical for industrial and commercial buildings, which are large energy users, and because the analys is is greatly simplified without detracting too much from its generality.

The general equilibrium heat-balance equation governing the surface temperature of a flat roof and thus the energy loss is given by (see also fig. 3)

$$
\alpha_{r} q_{\text {solar }}+\alpha_{r} q_{\text {sky }}+q=q_{\text {rad out }}+q_{\text {conv }}
$$

(All symbols are defined in appendix A.) Since remote measurement of a roof's thermal characteristics is being considered for energy loss detection, the prime concern is to determine $q$. However, the general equation has a solar input term $\mathrm{q}_{\text {solar }}$ so that it must be considered.

$$
\mathrm{q}_{\text {solar }} \approx 200 \mathrm{Btu} / \mathrm{hr} \mathrm{Et}{ }^{2}
$$

for a roof solar absorptance of approximately 1 . On the other hand the roof energy loss term $q$ is at most

$$
\mathrm{q}=\frac{1}{\mathrm{R}}\left(\mathrm{T}_{\text {in }}-\mathrm{T}_{\mathrm{r}}\right) \approx 12 \mathrm{Btu} / \mathrm{hr} \mathrm{ft}^{2}
$$

for an assumed $R=4$ and $\Delta T=48$. Thus it is readily apparent that, to isolate the parameters of interest and to enhance the accuracy of remote measurements, data should be acquired at night to eliminate a large source of radiation - the Sun.

Equation (1) under these conditions becomes

$$
\alpha_{r} q_{\text {sky }}+q=q_{\text {rad out }}+q_{\text {conv }}
$$

where now

$$
\begin{gathered}
q_{s k y}=\sigma T_{s}^{4} \\
q=\frac{1}{R}\left(T_{i n}-T_{r}\right)
\end{gathered}
$$




$$
\begin{gathered}
q_{\text {rad out }}=\varepsilon_{r} \sigma \mathrm{T}_{r}^{4} \\
q_{\text {conv }}=h_{v}\left(T_{r}-T_{a}\right)
\end{gathered}
$$

where $h_{v}$, the convective heat transfer coefficient, includes both forced and natural convection. Equation (2) assumes that incoming radiation is only from the sky. This assumption, of course, is only valid for a horizontal roof seeing only the sky. If other structures are within the field of view of the roof, both radiation view factors and effective structure temperatures must be incorporated into equation (2) in order to obtain the roof energy loss term q.

Collecting terms and assuming the roof surface acts as a gray body so that $\alpha_{r}=\varepsilon_{r}$ yield equation (2) as

$$
q=\frac{1}{R}\left(T_{i n}-T_{r}\right)=\varepsilon_{r} \sigma\left(T_{r}^{4}-T_{s}^{4}\right)+h_{v}\left(T_{r}-T_{a}\right)
$$

where $q$ now represents the flat-roof energy loss under night conditions and the roof surface temperature $T_{r}$ is the parameter that can be determined remotely.

To proceed with the analysis, two parameters, the effective sky temperature $T_{S}$ and the convective heat transfer coefficient $h_{v}$, must be specified. Effective sky temperatures for clear skies were found by using the formulation developed in reference 7 , namely,

$$
\mathrm{T}_{\mathrm{S}}=0.0412 \mathrm{~T} \frac{1}{\mathrm{a}} \cdot 5
$$

where the ambient air temperature is in degrees Rankine. The total convective heat transfer coefficient used is given by (refs. 8 and 9)

$$
\mathrm{h}_{\mathrm{v}}=0.29 \mathrm{v}+0.95
$$

where the velocity term $(0.29 \mathrm{v})$ represents the forced-convection component and the constant $(0.95)$, the free-convection component. A more detailed discussion of the background associated with these choices is given in appendix $\mathrm{B}$.

At this point sufficient information is available so that flat-roof temperatures can be calculated and trends established for clear-sky conditions.

\section{CALCULATION PROCEDURE}

Equation (3) is a quartic equation in the desired variable, the roof temperature $\mathrm{T}_{\mathrm{r}}$. As a result a programmable desktop computer was used with an iterative calculating procedure. The ranges of input variables used are

$$
\begin{gathered}
0<\varepsilon_{\mathrm{r}} \leq 1.0 \\
0<\mathrm{v} \leq 20 \mathrm{mph}
\end{gathered}
$$




$$
\begin{gathered}
450^{\circ} \leq \mathrm{T}_{\mathrm{a}} \leq 530^{\circ} \mathrm{R} \\
4 \leq \mathrm{R} \leq 20 \mathrm{hr} \mathrm{ft}^{2}{ }^{\circ} \mathrm{R} / \mathrm{Btu} \\
\mathrm{T}_{\mathrm{S}}=0.0412 \mathrm{Ta} \cdot 5\left(\mathrm{~T}_{\mathrm{a}} \mathrm{in}^{\circ} \mathrm{R}\right) \\
\mathrm{T}_{\mathrm{in}}=535^{\circ} \mathrm{R}(\text { design temperature recommended in ref. 8) }
\end{gathered}
$$

It is believed that these ranges of variables encompass the majority of environmental conditions of interest. The complete results of the calculations are presented in table I for those who may be interested in considering additional effects.

\section{PARAMETER EFFECTS ON FLAT-ROOF SURFACE TEMPERATURES}

To utilize aerial thermography to reliably detect excessive heat losses from flat roofs, it is necessary to understand how roof surface temperatures $\mathrm{T}_{\mathrm{r}}$ vary with the various controlling parameters: surface winds, ambient air temperature, sky temperature, the emittance of the roof surface, and the thermal resistance of the building roof. In particular it is necessary to investigate whether any variation of these parameters can cause any ambiguities such that roof surface temperatures are not a reliable indication of roof energy losses. Therefore the effect of varying the key parameters $v, T_{a}, T_{S}, \varepsilon_{r}$, and $R$ on roof surface temperatures will be. considered by using the procedure described in the preceding section.

The variation of $T_{r}$ with roof thermal resistance $R$ is shown in figure 4 for several ambient temperatures, wind speeds, and a roof surface emittance of 0.9 . The minimum roof thermal resistance ( $\left.R=4 \mathrm{hr} \mathrm{ft}^{2}{ }^{\circ} \mathrm{R} / \mathrm{Btu}\right)$ value shown represents current construction practice for flat roofs with no insulation. Roof surface temperatures for $R$ values greater than the minimum are predicted to be less than ambient air temperature. In addition, the greatest change in roof surface temperature occurs in the range $4 \leq R \leq 13$. Therefore, for the rest of this analysis, only two values of $\mathrm{R}$ ( 4 and $13 \mathrm{hr} \mathrm{ft}^{2}{ }^{\circ} \mathrm{R} / \mathrm{Btu}$ ) will be considered since these two values represent approximately the maximum change to be expected in $T_{r}$ due to $R$. In addition, in figure 4 ambient air temperature and surface wind speeds consistently change the level of $T_{r}$, but the trends remain the same. Therefore typical values of $\mathrm{T}_{a}$ and $\mathrm{v}$ can be used to evaluate the effects of other parameters on $T_{r}$.

The effect of roof surface emittance $\varepsilon_{r}$ on $T_{r}$ is shown in figure 5 for all possible emittances. When this full range is considered, there is a sizable change in $T_{r}$. However, such a large emittance variation is not representative for roof surfaces. Typical emittances for nonmetallic roofs 1 ie between 0.9 and 0.96 (appendix B). For these values the effect of emittance on $T_{r}$ is less than $1^{\circ} R$. Thus trends of $T_{r}$ with other parameters can be reliably evaluated by using any emittance in this range.

Figure 6 shows the variation of $T_{r}$ with ambient air temperature. For typical thermal resistance values, $\mathrm{T}_{\mathrm{r}}$ is at all times less than the ambient air temperature $T_{a}$ for the clear-sky condition. In addition, as 
would be expected, the $T_{r}$ for a low $R$ (high heat loss) is always higher than the $\mathrm{T}_{r}$ associated with a high $\mathrm{R}$ (low heat loss).

Surface wind speed $v$ affects $T_{r}$ as shown in figure 7. Although high wind speeds drive the roof surface temperatures closer together for typical thermal resistances, a $1^{\circ} \mathrm{R}$ difference still existed at high wind speeds. In addition, regardless of surface wind speed, the roof temperatures for low $R$ 's were always higher than those associated with high $R^{\prime} s$. The range of roof emittances is shown to reemphasize that the effect

of $\varepsilon_{r}$ was small and caused no ambiguities in $T_{r}$ to occur.

Figures 4 to 7 have demonstrated that with the generally anticipated environmental conditions or thermal parameters, roof surface temperatures vary as you would expect - high roof temperatures are associated with low $\mathrm{R}^{\prime}$ 's and low roof temperatures with high $\mathrm{R}^{\prime} \mathrm{s}$. In other words, no ambiguities in roof surface temperatures occur because of the environmental conditions or roof thermal properties. The argument can be finalized by showing what is probably obvious to most users. The energy flux varies directly with roof surface temperature for a given set of environmental conditions and roof thermal properties. Figure 8 shows the variation of roof heat flux $q$ with wind speed. It is readily evident that the heat flux associated with the low $R$ is larger than that associated with the high $R$ and that the emittance effect is very small. In addition, the effect of wind speed is also very small because the radiative effect is dominant for clear skies.

Even though some of the parameter values and correlations used in the analysis (in particular for $\mathrm{h}_{\mathrm{y}}, \mathrm{q}_{\mathrm{s}}$, and $\varepsilon_{\mathrm{r}}$ ) may be questioned, the trends indicated are proper and therefore useful. Thus it can be concluded that, if the surface temperature of a flat roof can be determined either by direct or remote measurements, it can be directly related to the energy being lost. Specifically a roof section having a temperature higher than another roof section is losing more heat. However, when remote measurements are used to determine roof temperatures, there is a caveat. Remote measurements of radiation from a rooftop do not directly yield the roof surface temperature but rather yield an effective temperature that is related to the total radiant flux coming from the surface. This flux, which produces thermographs, is related not only to the roof surface temperature but also to the envirommental conditions and roof thermal properties. Because of this, remotely acquired thermography may or may not depict the actual roof energy losses associated with roof surface temperatures. As a result the effect of environmental conditions and roof thermal properties on the radiant flux seen by a remote detector must be considered in order to define those conditions that are conducive to acquiring reliable aerial thermography for the detection of energy losses.

\section{ENVIRONMENTAL CONDITIONS REQUIRED FOR RELIABLE AERIAL THERMOGRAPHY}

The reliability of aerial thermography can be discussed from two relatively unrelated positions - from a technical standpoint and from a user community viewpoint. As will be developed, each requires a different approach. From a technical perspective the energy loss of interest can be determined from the data even though a thermograph does not show it clear1y. The technical approach consists of using a densitometer to obtain film density and then the effective temperature or, if the data are in digital 
form, printing out the effective temperatures for each pixel (digital picture element). With such data the energy loss can be determined with an accuracy consistent with the accuracy associated with the instrumentation, the environmental parameters, and the relationship used (refs. 10 and 11). Perhaps the point to emphasize for the technical approach is that, in principle, energy losses can be determined even when the thermograph does not visually show the losses clearly.

On the other hand, if aerial thermography is to be used by a community to promote energy conservation, reliable imagery (i.e., imagery with good visual and heat loss discrimination) is of the utmost importance - in fact, mandatory. A user must be able to look at the synoptic thermal image and easily locate his building among all the other buildings and then determine whether any energy losses associated with the roof of his building are significant. In particular, he must be able to compare his roof loss with a reference loss to convince himself that indeed his building roof is losing energy at an unacceptable rate. If the imagery cannot be interpreted easily by the user, it does not have sufficient credibility and the user cannot be easily induced to enter into an energy conservation program and make what may be expensive alterations or renovations. To sumnarize the user viewpoint - reliable thermography must clearly accomplish two goals:

(1) It must have good visual discrimination (i.e., buildings $c$ an be clearly identified against the background).

(2) Heat losses must be easily seen (i.e., the imagery must have good heat loss discrimination). To illustrate the point being made, refer again to figure $2(\mathrm{a})$. This is a thermograph of a sizable area having many houses and several small businesses. The structures within the scene cannot be identified in the thermograph with any degree of assurance. To attempt to implement an energy conservation program with such imagery would be futile because the user community could not be convinced to cooperate with such imagery. The imagery is totally lacking good discrimination properties and hence has no credibility with the user community. Therefore, since aerial thermography is being used extensively to promote energy conservation in the public sector (the user community), the remaining discussion focuses on the environmental conditions required to obtain thermography that has both good visual and heat loss discrimination properties. The ground rules for such a development can be established by discussing more fully, first, what radiation produces the imagery and, second, what constitutes good discrimination properties in imagery.

First, it is important to understand that remotely obtained imagery, as used in energy conservation programs, is produced by both the energy emitted by a terrestrial object because of its temperature and the incoming sky energy reflected by the object (fig. 3 ). Thus the energy seen by a remote detector is

$$
q_{e f f}^{\prime}=q_{e m i t t e d}^{\prime}+\rho^{\prime} q_{s}^{\prime}
$$

and specifically, since most thermal detectors measure or see only in the 8to 14-micrometer wavelength region (primes designate the 8- to 14- $\mu \mathrm{m}$ region), the temperatures associated with the fluxes are (ref. 11)

$$
C T_{\text {eff }}^{5}=C \varepsilon^{\prime} T^{5}+\left(1-\varepsilon^{\prime}\right) q_{s}^{\prime}
$$


As a result, equations (6) and (7) demonstrate that a thermograph is related not only to an object's surface temperature but also to other parameters. As a consequence a thermograph may or may not be directly correlated with an object's heat loss.

With this in mind the concept of discrimination can be developed. Visual discrimination, the ability to delineate building rooftops from the general scene background, is defined by the effective temperature difference existing between rooftops and the overall scene background $\left(\mathrm{T}_{\mathrm{r}}\right.$, eff $\left.\mathrm{T}_{\mathrm{b}, \text { eff }}\right)$. For large temperature differences, buildings are easily seen. As the temperature difference approaches zero, it becomes more and more difficult to discern buildings from the background. Heat loss discrimination is defined as the temperature difference between a well-insulated rooftop $(R \approx 13)$ and a poorly insulated rooftop $(R \approx 4)\left(T_{r}\right.$, eff $(R=13)-$ $\left.\mathrm{T}_{\mathrm{r}, \text { eff }}(\mathrm{R}=4)\right)$.

The roof thermal resistances used were selected on the basis of the following arguments: A value of $R=4$ is approximately the minimum value obtainable with current construction practices (ref. 8). A value of $R=13$ is the maximum that need be considered since any changes in temperature due to a larger $R$ value are small (fig. 4). Thus the energy loss discrimination is good for imagery showing large temperature differences between the losses associated with these $\mathrm{R}^{\prime} \mathrm{s}$ and is poor for small temperature differences.

With the definitions of discrimination established, the analytical results, previously presented, $c$ an be used to establish the environmental conditions favorable for obtaining reliable thermography under clear-sky conditions. Of course, because all possible environmental conditions cannot be discussed, only the important parameters, surface wind velocity and ambient air temperature, are considered.

Effective roof surface temperatures $T_{r, e f f}$ were calculated from equation ( 7$)$ and the actual roof temperatures were obtained from equation (3). A roof spectral emittance $\varepsilon_{\mathrm{r}}^{\prime}$ range of 0.94 to 0.96 was used (appendix $B$ ). The spectral sky fluxes $q_{S}^{\prime}$ needed to implement equation (7) are presented in table II and were obtained in a private communication with Richard Goldstein of the University of Minnesota.

Typical results are shown in figure 9 for an ambient air temperature of $490^{\circ} \mathrm{R}$ and wind velocities as high as 20 miles per hour. Heat loss discrimination is discussed first. No confusion exists in the effective roof temperatures (so the thermography should be reliable) until a velocity of approximately 15 miles per hour is approached. At that point the $R=13$, $\varepsilon_{r}^{\prime}=0.96$ effective roof temperature becomes larger than the $R=4, \varepsilon_{r}^{\prime}=0.94$ effective roof temperature, an indication that the $R=13$ heatloss is larger than the $R=4$.

Of course, this cannot be true and is due to the interaction between parameters in equation (7). Thus this crossover point becomes the threshold for reliable heat loss discrimination. From this criterion several conclusions oncerning heat loss discrimination can be deduced from figure 9:

(1) For surface wind speeds less than 15 miles per hour effective roof temperatures are seen by an 8- to 14-micrometer wavelength detector in the proper order, that is, the $\mathrm{R}=4, \varepsilon=0.94$ effective temperatures are higher than the $\mathrm{R}=13, \varepsilon=0.96$ effective temperatures.

(2) Heat loss discrimination is reliable for surface wind speeds less than 15 miles per hour. It becomes better as the velocity decreases to zero. 
(3) If imagery is obtained beyond the threshold ( $>>15 \mathrm{mph}$ ), a small energy loss $(R=13)$ can be identified as a large energy loss and vice versa.

(4) In addition, the 15-mile-per-hour threshold velocity insures good heat loss discrimination between all roof surfaces with $R$ values greater than 13 and all roof surfaces with $R$ values equal to 4 since the threshold occurs at a higher velocity. A heat loss discrimination curve based on this criterion has been drawn as shown in figure 10 for surface wind velocities as high as 20 miles per hour and ambient air temperatures ranging from approximately $460^{\circ}$ to $540^{\circ} \mathrm{R}$. Obtaining thermographs with environmental conditions to the left of this curve should insure reliable thermography for heat loss discrimination.

To define visual discrimination ( $T_{r}$, eff $\neq T_{b}$, eff $)$, knowledge of the average effective background temperature is required. From studies of a large number of NASA Lewis' thermographs obtained under sundry environmental conditions, the following correlation was found to reasonably predict the average effective background temperature:

$$
\mathrm{T}_{\mathrm{b}, \mathrm{eff}}^{5}=\varepsilon_{\mathrm{b}} \mathrm{T}_{\mathrm{a}}^{5}+\frac{\left(1-\varepsilon_{\mathrm{b}}\right) \mathrm{q}_{\mathrm{s}}^{\prime}}{\mathrm{c}}
$$

where the average background emittance $\varepsilon_{\mathrm{b}}$ was found to be $0.92 \pm 0.01$ over the ambient air temperature range considered. Admittedly such a correlation is only an estimate and requires further analysis before an accurate effective background temperature can be determined. However, at this time such an effort is not warranted since the environmental parameters are not known nearly as well and are more important (e.g., $\mathrm{T}_{\mathrm{S}}, \mathrm{q}_{\mathrm{S}}^{\prime}$, and $\mathrm{h}_{\mathrm{v}}$; appendix B).

With a reasonably effective background temperature defined (eq. ( 8 )), visual discrimination criteria can be established. To do this, figure 9 will be used again with the effective background temperature shown (fig. 11). In general, effective roof temperatures are lower than the background temperature. However, at a surface wind speed of approximately 15 miles per hour, the $\mathrm{R}=4, \varepsilon_{\mathrm{r}}^{\prime}=0.96$ effective roof temperature becomes higher than the background temperature. Thus as with heat loss discrimination this crossover point becomes the threshold for visual discrimination. Any velocity less than the crossover velocity yields good visual discrimination for all $R$ values greater than 4 and any roof surface emittance less than 0.96. The visual discrimination curve based on this criterion is shown in figure 12. Thermography obtained at environmental conditions to the right of this threshold curve should be reliable and have good visual discrimination. Now, by putting both discrimination curves together, we can clearly see the environmental conditions required to insure thermography having both good visual and good heat loss discrimination. The operational map obtained is presented in figure 13. Operation within the crosshatched area should have the highest probability of obtaining reliable thermography suitable for interaction with the user community. The complete operational map can be used to explain what on occasion has been seen in thermographs. For example, at ambient air temperatures around $480^{\circ} \mathrm{R}$ (a popular range for obtaining thermography), discrimination is good for velocities less than about 10 miles per hour. At about 10 miles per hour visual discrimination becomes poor, yet heat loss discrimination is still 
good. Heat loss discrimination becomes progressively poorer as the heat loss discrimination curve is approached.

The relevancy of the analytically derived operational map was tested by using many of the thermographs obtained in the NASA Lewis aerial thermography program as well as selected examples obtained from Texas Instruments, Inc. (personal communication from James Evans). These data, which are shown in figure 14, indicate that the derived operational map is reasonable. The

five Texas Instrument points that 1 ie on the threshold curve for visual discrimination (meaning that visual discrimination should be poor) can be explained by noting that this is exactly what would happen if good visual discrimination had been determined from the thermographs of an $R=13$ rooftop. Recall that the visual discrimination threshold curve was defined for an $R=4$ rooftop and in so doing gave the lowest possible velocity, for a given ambient temperature, at which confusion could be seen. The visual discrimination threshold for an $\mathrm{R}=13$ rooftop occurs at a much higher velocity (fig. 11).

The comparison of experiment and theory can be further illustrated by considering the thermograph represented by the solid square. This point should have marginal visual discrimination and reasonable heat loss discrimination. The actual thermograph is shown in figure $1(a)$. Note that the flat roof of the school has reasonable heat loss discrimination; however, the visual discrimination is poor; that is, the school building is almost indistinguishable from the overall background.

Now consider the thermograph for the same school but obtained under different environmental conditions - the solid circle in figure 14. On the basis of the analytical results this thermograph should have complete discrimination. As shown in figure $1(b)$ it does indeed have both good visual and good heat loss discrimination. Note how clearly the school building is delineated against the overall scene background and the striking contrast (or temperature difference) in energy losses on the school roof.

The operational map for obtaining thermography with good discrimination properties has been incorporated into a suggested set of specifications (appendix $C$ ) that may be used for the guidance of those who wish to use aerial thermography for energy conservation programs.

\section{CONCLUDING REMARKS}

The following remarks and recommendations are made for the guidance of those who are considering the use of aerial thermography. Adherence to the recommendations made herein should insure reliable thermography for use in a user-oriented energy conservation program.

Analytical results for typical commercial and industrial flat roofs have been presented to illustrate that the trends of roof surface temperatures and/or roof energy losses should be clearly evident for low wind speeds and low ambient air temperatures. In addition, the analysis shows that representative roof surface emittances $\left(0.9<\varepsilon_{\mathrm{r}}<1.0\right)$ do not alter the roof temperatures significantly, and thus variations in roof emittances should neither be troublesome nor cause confusion in identifying and interpreting roof energy losses. Specifically, it is shown that, when realistic roof emittances are used, the differences in roof temperature associated with the roof thermal resistance are not masked as long as the roof thermal resistance is less than $R=13$. Above this value, changes in 
roof temperature are very small and the probability of confusion great, but fortunately aerial thermographic surveys are of little interest for detecting the small energy losses associated with large roof thermal resistances. Guidelines for aerial thermographic surveys cannot be based on the actual roof surface temperature. A remote detector measures not the actual temperature but an effective temperature that is related to the actual temperature through the roof's thermal properties and the environmental conditions. An investigation of effective roof temperature trends does indeed show that variations in roof emittance and environmental conditions $c a n$ cause confusion in identifying and interpreting roof energy losses. However, by defining both visual and heat loss discrimination, an operational map relating surface wind speed and ambient air temperature at which reliable aerial thermography can be acquired was derived. It shows, for example, that at a fixed wind velocity, a low ambient air temperature yields thermographs that can clearly identify and discriminate energy losses but that do not clearly define building outlines. Acquisition at a slightly higher air temperature produces thermographs that easily discriminate both structures and energy losses. Yet, at still a slightly higher air temperature, the imagery obtained does not permit energy losses to be easily discriminated. A comparison of many experimental data points with the derived operational map showed very good agreement.

Even though several parameters required to implement the analysis must be estimated, the trends predicted are felt to be reliable and proper. Thus adherence to the operational map, which outlines the key environmental conditions (wind velocity and ambient air temperature) conducive to acquiring reliable thermography, should insure imagery having both good and proper discrimination properties. Such imagery can then be used easily and confidently by the user community to promote an energy conservation program. 


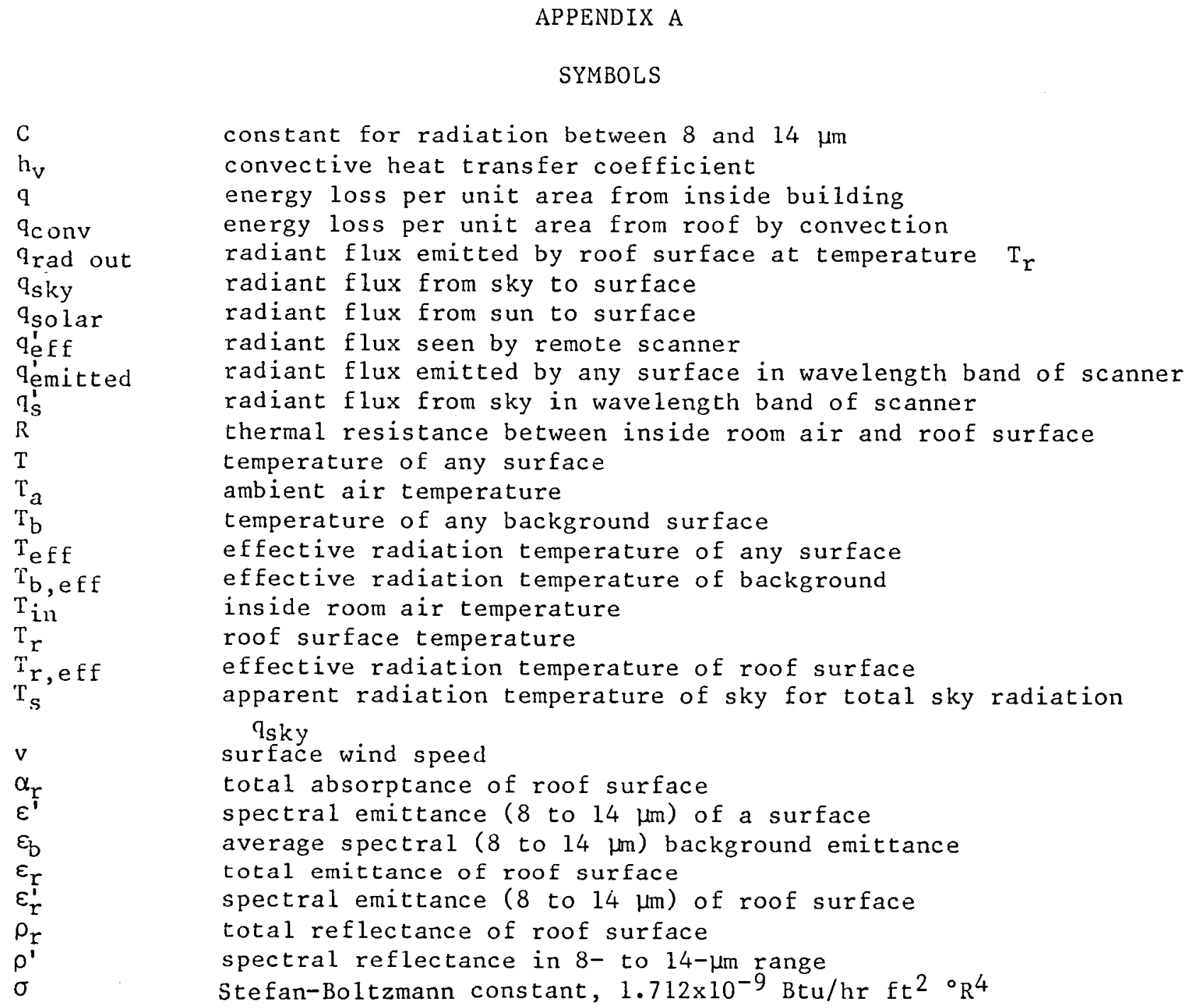


APPENDIX B

\section{ANALYSIS CONSIDERATIONS AND RECOMMENDATIONS}

An analytical study was performed on the heat loss from a flat roof by using a heat-balance equation. In this study, roof surface temperatures were calculated from a range of roof thermal parameters and environmental conditions. In addition, roof temperatures were related to the roof's radiant flux (effective radiation temperature) that would be seen by a therinal detector in the 8- to 14-micrometer wavelength band. The purpose, of course, was to develop an operational map that defines the limits (or envelope) of the environmental conditions necessary to obtain reliable thermal imagery.

To perform the analyses, the parameters $h_{\mathrm{v}}, \varepsilon_{\mathrm{r}}, \mathrm{T}_{\mathrm{s}}, \varepsilon^{\prime}$, and $\mathrm{q}_{\mathrm{s}}^{\prime}$ (see eqs. (3) and (7)) had to be estimated. At present, however, there is considerable uncertainty associated with this selection process. A general discussion of some of these uncertainties and the background involved in the parameter selection process is presented.

\section{Sky Radiation}

One of the important parameters in the heat-balance equation (eq. ( 1 )) is the total radiation (for all wavelengths) from the clear night sky $\mathrm{q}_{\text {sky }}$. This sky flux is commonly considered in terms of a calorimetric sky temperature $T_{S}$ as in equation (3). Several studies of this key variable have been made (refs. 7 and 12, and an unpublished study by Richard Goldstein of the University of Minnesota), and the results are shown in figure 15 . As shown, the three models predict values of $\mathrm{T}_{\mathrm{S}}$ that differ by almost $30^{\circ} \mathrm{R}$ for an ambient air temperature of $490^{\circ} \mathrm{R}$. The Swinbank correlation was selected to calculate the roof surface temperature trends because it is based on over 100 experimental points and because it reasonably approximates both Bliss and Goldstein.

To relate the roof surface temperature to the effective radiation temperature of the roof as measured by a remote detector, a spectral sky flux $\mathrm{q}_{s}^{\prime}$ (eq. (7)) must also be selected. The spectral sky flux is only that portion of the total sky radiation in the wavelength region sensed by a remote detector. Since a remote detector measures radiant flux in a wavelength region where the atmospheric absorption, and hence emission, is small, q's for a clear sky will be much less than the total (calorimetric) sky flux. The spectral sky flux is a critical parameter in the development of discrimination criteria. However, it is difficult to specify $q_{s}^{\prime}$ since it depends on the amount of water vapor and carbon dioxide in the atmosphere and on the air pressure and temperature. Several studies have been made of the spectral sky flux from clear night skies. Sloan (refs. 13 and 14) presents spectral data for a limited number of temperatures and relative humidities. Goldstein has calculated $q_{S}^{\prime}$ based on a standard atmosphere, and Buettner (ref. 15) presents a method for calculating $q_{s}^{\prime}$ if certain atmospheric parameters are known. Basically, no studies can be found in the literature that present experimental values of $q_{s}^{\prime}$ for the range of atmospheric conditions encountered in obtaining thermographic data. Therefore the spectral sky fluxes calculated by Goldstein based on a standard atmosphere were used to determine effective radiation temperatures. 
Roof Surface Emittance

There are two emittances required to do the analysis: the spectral emittance $\varepsilon^{\prime}$ to obtain the effective radiation temperature from the actual surface temperature (eq. (7)) and the total emittance of a roof surface $\varepsilon_{\mathrm{r}}$ to predict the roof surface temperature (eq. (3)).

The spectral emittance $\varepsilon^{\prime}$ is the emittance for the wavelength region ( 8 to $14 \mathrm{\mu m}$ ) seen by the remote detector. Table III lists emittance values available in the literature as well as measurements made at Lewis. Where possible, the wavelength ranges covered by the measurements are also listed in the table. Even though the emittances are not limited to the 8- to 14-micrometer wavelength range, most nonmetallic roof materials are considered to behave as gray bodies for wavelengths longer than 5 micrometers, so that the listed values are appropriate spectral emittances. The Lewis measurements were made by using a commercially available instrument that measures over the wavelength range 5 to 25 micrometers. Transfer standards were used to calibrate the instrument on the site for each series. Again, with the gray body assumption these measurements are considered valid for the 8- to 14-micrometer region. Since the Lewis measurements were made on actual rooftops, and since they are also in substantial agreement with similar measurements listed in table III, a spectral emittance range of 0.94 . to 0.96 was used to obtain the effective surface temperatures (eq. ( 7 )).

The total emittances for some materials and surfaces are listed in table III. Most measurements listed, however, are for a finite wavelength range. This is not a problem since most flat roof surfaces behave as gray bodies, so that finite wavelength emittances are frequently used as total emittances. In particular the Lewis emittance measurements should be reasonable since less than 1 percent of the radiant flux from a surface at a representative temperature is at wavelengths less than 5 micrometers. Since most of the measurements gave roof surface emittances between 0.90 and 0.96 , this range was used for calculating roof surface temperatures. Because for $\varepsilon_{\mathrm{r}}>0.9$ the emittance effect on the surface temperature (and heat loss) is very small, a precise value for total emittance is not required.

\section{Convective Heat Transfer Coefficient}

The convective heat transfer coefficient $h_{v}$ required in equation ( 3 ) is a function of many variables: ambient air temperature, wind speed, surface texture, the geometry of the surface, and the state of the airflow (i.e., whether it is laminar or turbulent). In addition, the convective heat transfer coefficient used must account for two heat transfer processes: that due to free convection, and that due to forced convection. The functional forms of $h_{v}$ generally found in the literature and used are greatly simplified and do not consider all the variables. Thus the coefficients obtained are highly questionable.

Figure 16 shows the results from two models found in the literature. They are based on heat transfer for airflow over a smooth, horizontal flat plate. The ASHRAE (ref. 8) formulation, perhaps the most commonly used model, is based on data for a plate 1 foot square. On the other hand, Goldstein's (ref. 11) calculations are based on turbulent boundary layer flow and yield a local forced convection coefficient for each position on a flat plate. The free-convection coefficient, calculated for a temperature difference of $10^{\circ} \mathrm{R}$ 
(ref. 11), has been added to the forced-convection coefficient to give the total $h_{v}$ shown in figure 16. For short plate lengths both formulations agree reasonably well for all wind speeds considered. For longer lengths (as would be encountered on rooftops) there are large differences at high wind speeds.

To pursue these differences in more detail, the coefficients predicted by both turbulent and laminar boundary layer theory are compared with those predicted by the simple expression presented in the ASHRAE manual (ref. 8). According to boundary layer theory (ref. 16) the forced-convection coefficients for both turbulent and laminar flow are given by

$$
h_{x}=\left[\frac{0.296(\operatorname{Re})_{x}^{4 / 5}(\mathrm{Pr})}{1+1.31(\mathrm{Pr})^{-1 / 6}(\operatorname{Re})_{\mathrm{x}}^{-1 / 10}(\mathrm{Pr}-1)}\right] \frac{\mathrm{k}}{\mathrm{x}} \quad \text { (turbulent) }
$$

and

$$
h_{x}=0.332(P r){ }^{1 / 3}(\operatorname{Re}){ }_{x}^{1 / 2}\left(\frac{k}{x}\right) \quad(1 \text { aminar })
$$

where
$(\text { Re })_{x} \quad$ Reynolds number
$\operatorname{Pr} \quad$ Prandt 1 number
$k \quad$ thermal conductivity of air
$x \quad$ distance from leading edge of plate

Both coefficients are a function of the Reynolds number $(\operatorname{Re})_{x}$, which is dependent on both wind speed and the length of a run to a given position on a plate. Figure 17 shows the comparison between the ASHRAE and boundary layer predictions for a 1-foot length with variable surface wind speed. Even for the 1-foot distance there are differences between the models. Figure 18 shows this comparison with surface wind speed held constant and the length of the run varied. For this condition the ASHRAE formulation gives a constant value based on a 1-foot length. On the other hand, boundary layer theory predicts that $h_{v}$ decreases with increasing $R e$ (or increased length of run). As a result there are large differences between the predicted values, in particular for laminar flow. Because of the uncertainties in the convection coefficient noted in the preceding analytical comparison, a heat transfer experiment was performed in an attempt to gain some insight into the problem. For the experiment a flat, electrically heated panel was instrumented so that surface temperatures and local heat fluxes could be measured. Temperatures were measured with copper-Constantan thermocouples, and commercially available heat flow sensors were used to obtain heat fluxes. The surface was coated with a material of known high emittance $(0.96)$ so that the heat loss due to emitted radiation could be calculated more accurately. In addition, ambient air temperature and wind speed were also measured.

Experimental data were obtained with clear-sky conditions and steady wind speeds. The electrical heaters were used to maintain surface temperatures 
constant to $\pm 2^{\circ} \mathrm{R}$ over the test surface. When an equilibrium plate temperature was attained, the heat flux sensor data were recorded. Data were recorded each night for three panel temperatures, including one set with the panel surface temperature nearly equal to the ambient air temperature. The latter test condition $\left(T \approx T_{a}\right.$ ) minimizes the convection component so that the background radiation (from sky, buildings, etc.) to the plate can be determined. With this background flux and the other two test conditions, the local convection coefficient can be obtained.

Data were not obtained over a wide enough range of wind speeds to make a correlation of $h_{x}$ with wind speed. However, enough data were obtained so that the local convection coefficient for a constant wind speed could be determined. A typical data set is shown in figure 19. The experimental coefficient contains both the free- and forced-convection terms. For comparison, a free-convection component calculated from $\mathrm{H}($ free $)=0.29 \Delta \mathrm{T} 1 / 3$ (ref. 11) has been added to the coefficient for forced turbulent convection where the experimental $\Delta \mathrm{T}$ was $10^{\circ} \mathrm{R}$. Even with the scatter in the experimental data a comparison of experiment with the empirical correlations shows rough agreement; that is, the experimental points are bracketed by the laminar and turbulent predictions. Even so, it must be remembered that these results are for a horizontal flat plate and may not truly represent a flat roof, which frequently has a parapet around its edge along with other obstructions that would significantly alter the state of the flow. A much more controlled and accurate experiment is required to realistically evaluate the convective heat transfer for a flat roof.

\section{Summary}

A general discussion of some of the uncertainties involved in selecting the parameters $h_{v}, \varepsilon_{r}, T_{S}, \varepsilon^{\prime}$, and $q_{s}^{\prime}$ was presented. In general, additional information is required to more accurately describe each of the parameters. In spite of the uncertainities involved in the selection process, it is felt that the values and functional forms used were reasonable and adequately predicted the trends. As more accurate values for the parameters become available, the procedure described in the text can be used to generate a new operational map. 


\section{APPENDIX C}

RECOMMENDATIONS AND PROPOSED SPECIFICATIONS FOR USING AERIAL THERMO-

\section{GRAPHY TO DETECT ENERGY LOSSES}

The following recommendations and proposed specifications are presented for the guidance of those who have made the commitment to use aerial thermography for energy conservation.

The initial step, and perhaps the most important step that can be taken to implement an effective program, is to seek the advice of those who have managed major programs. These managers, listed in reference 5 , have a wealth of experience in securing a contractor, setting contract specifications, and selecting the imagery and transfer methodology for public outreach programs. Additional information concerning major thermography programs can be found in a recently available DOE report (ref. 17).

A proposed set of specifications follows. These specifications may be used as an initial guide in establishing requirements for future programs.

\section{Scope}

Purpose. - Aerial thermography shall be acquired to detect energy losses from building roofs and from high-temperature water and steam heating lines both below and above ground.

Work covered. - Al1 plant, superintendence, labor, equipment, and materials required for an aerial survey to detect energy losses and to provide the desired products shall be specified.

\section{General Data}

Location. - The cities to be surveyed shall be specified by the user. City descriptions. - The area to be surveyed in each city is delineated by the boundaries shown on the enclosed map.

\section{Environmental Conditions}

The environmental conditions shall be documented at the beginning and end of each flyover and hourly during data acquisition.

Weather. - Overflights shall be made when weather conditions are appropriate for obtaining quality imagery that permits good visual discrimination of structures and good temperature discrimination of energy losses. A safe rule of thumb for weather conditions is to have an ambient air temperature less than $495^{\circ} \mathrm{R}$, clear skies, calm winds, and a dewpoint spread of at least $5^{\circ} \mathrm{R}$. There shall be no snow or water on the roofs. The specific permissible surface winds and ambient temperatures for clear-sky conditions are shown in the discrimination map (fig. 13).

Time. - Data shall be acquired between $9 \mathrm{p} \cdot \mathrm{m}$. and 3 a.m. from October 15 to April 1.

\section{Ground Support}

All ground support of the overflights shall be supplied by the contractor. 
Flight Data

The following data shall be recorded and supplied for each overflight:

(1) City

(2) Flight line numbers

(3) Map of city showing flight lines as flown

(4) Date and time of beginning and end of each overflight

(5) Aircraft altitude above ground level for each overflight

(6) Aircraft bearing for each flight line

(7) Ground-level ambient air temperature, wind speed and direction, and dewpoint temperature at the beginning and end of each overflight

\section{Quality of Imagery}

Data recording. - Data shall be recorded directly from the scanner onto magnetic tapes and/or roll film suitable for postflight analysis (to be chosen by the user). Data shall be calibrated so that relative or absolute radiant energy can be obtained from all structures of interest. Automatic gain systems shall not be used.

Processing. - Taped data shall be transferable to photographic film or usable for computer processing. Processing shall include a density level slicing that will achieve both good heat loss discrimination and good visual discrimination. Processing can result in either black-and-white or colorcoded imagery (to be chosen by the user).

Imagery requirements. - Spatial resolution of the scanner shall be equal to or less than 2.5 feet. In addition, both visual and heat loss discrimination, as discussed herein, must be good. Thermal imagery shall be obtained in the 8- to 14-micrometer wavelength region and must be capable of depicting temperature differences as small as $1^{\circ} \mathrm{R}$. The scale of the finished product shall be specified by the user so that the thermographs can be easily interpreted visually without special equipment.

Flight line requirements. - Flight lines shall be planned by the contractor so that the ground coverage of each scan line is contiguous with the next and does not exceed a side-to-side field of view of $90^{\circ}$. Adjacent flight lines shall have side overlaps of at least 15 percent so that a good mosaic of the imagery can be constructed. Flight lines shall be in the same direction and generally parallel to major streets within the survey area.

\section{Reporting}

The method used to determine effective radiation temperature from film density shall be described if black-and-white imagery is used. The effective radiation temperature range for each color shall be supplied if color coding is used. The overflight data, the imagery, and a full interpretation of a representative energy loss situation for each city shall be documented in a final report to be delivered within a specified number of weeks after the overflight. All flight data, data tapes, and imagery negatives shall be provided with the report. 


\section{REFERENCES}

1. Jack, J. R.; and Bowman, R. L.: Application of Thermal Scanning to the NASA LeRC Energy Conservation Program. AIAA Paper 75-744, May 1975 .

2. Bowman, R. L.; and Jack, J. R.: Application of Thermal Scanning to the NASA LeRC Energy Conservation Program. Presented at the NASA Energy Reduction Coordinators Meeting, NASA Lewis Research Center, Cleveland, Ohio, June 25, 1975.

3. Bowman, Robert L.; and Jack, John R.: Application of Remote Thermal Scanning to the NASA Energy Conservation Program. NASA TM X-73570, 1977.

4. Jack, John R.: NASA's Program on Aerial Thermography for Energy Conservation. Presented at the 1978 ACSM-ASP Annual Technical Meeting, Albuquerque, New Mexico, Oct. 15-21, 1978.

5. Jack, John R.: Aerial Thermography for Energy Conservation. NASA TM-78959, 1978.

6. Jack, John R.; and Bowman, Robert L.: Effective Aerial Thermography for Energy. Presented at the Second National Conference on Thermal Infrared Sensing Technology for Energy Conservation Programs, Albuquerque, New Mexico, Nov. 7-9, 1979.

7. Swinbank, W. C.: Long-Wave Radiation from Clear Skies. Q. J. R. Meteorol. Soc., vol. 89, no. 381, July 1963, pp. 339-348.

8. ASHRAE Handbook of Fundamentals. American Society of Heating, Refrigerating and Air Conditioning Engineers, 1972.

9. Headley, R. B.; et a1.: Infrared Thermography Requirements Study for Energy Conservation. CONS/2109-1, Energy Research and Development Admin., 1977.

10. Bowman, Robert L; and Jack, John R.: Feasibility of Determining Flat Roof Heat Losses Using Aerial Thermography. NASA TM-79152, 1979.

11. Goldstein, Richard J.: Application of Aerial Infrared Thermography to the Measurement of Building Heat Loss. ASHRAE Trans., vol. 84, pt. 1, 1978, pp. 207-226.

12. Bliss, R. W., Jr.: Atmospheric Radiation Near the Surface of the Ground: A Summary for Engineers. Sol. Energy, vol. 5, 1961, pp. $103-120$.

13. Sloan, Raymond W.: The Infrared Emission Spectrum of the Atmosphere. Sci. Rep. 3, Ohio State Univ. Research Foundation, 1956. (AFCRC-TN-56-474.) 
14. Sloan, Raymond; Shaw, J. H.; and Williams, Dudley: Infrared Emission Spectrum of the Atmosphere. J. Opt. Soc. Am., vo1. 45, no. 6, June 1955, pp. 455-460.

15. Buettner, Konrad J. K.: The Determination of Infrared Emissivities of Terrestrial Surfaces. J. Geophys. Res., vol. 70, no. 6, Mar. 15, 1965, pp. 1329-1337.

16. Eckert, E. R. G.; and Drake, Robert M., Jr.: Heat and Mass Transfer. Second ed., McGraw-Hill Book Co., 1959.

17. Snow, F. J.; Wood, J. T.; and Barthle, R. C.: Status of Thermal Imaging Technology as Applied to Conservation - Update 1. DOE/CS-20413/01, U.S. Dept. of Energy, July 1980.

18. Gubareff, G. G.; Janssen, J. E.; and Torborg, R. H.: Thermal Radiation Properties Survey. Honeywell Research Center, MinneapolisHoneywel1 Regulator Co., Minneapolis, Minn., Second ed., 1960.

19. Wolfe, William L., ed.: Handbook of Military Infrared Technology. Office of Naval Research, Department of the Navy, Washington, D.C., 1965.

20. Schott, John R.: Aerial Measurement of Heat Loss. Calspan Report 6393-M, Calspan Advanced Technology Center, July 1979.

21. Wolfe, William L.,; and Zissis, George J., eds.: The Infrared Handbook. Office of Naval Research, Department of the Navy, Washington, D.C., 1978 .

22. Kondratyev, K. Ya: Radiation in the Atmosphere. Academic Press, Inc., 1969 .

23. Hudson, Richard D., Jr.: Infrared System Engineering. John Wiley \& Sons, 1969. 
table t. - calculated roof surface temperatures

(a) $\mathrm{R}=4.0 \mathrm{hr} \mathrm{ft}^{2}{ }^{\circ} \mathrm{R} / \mathrm{Bt}$

\begin{tabular}{|c|c|c|c|c|c|c|}
\hline \multirow{3}{*}{$\begin{array}{c}\text { Amibent air } \\
\text { temperature, } \\
T_{a} \text {, }\end{array}$} & \multirow{3}{*}{$\begin{array}{c}\text { Total } \\
\text { emittance } \\
\text { of roof } \\
\text { surface, } \\
\varepsilon_{\mathrm{r}}\end{array}$} & \multicolumn{5}{|c|}{ Surface wind speed, $v, \mathrm{mph}$} \\
\hline & & 0 & 5 & 10 & 15 & 20 \\
\hline & & \multicolumn{5}{|c|}{ Roof surface temperature, $T_{r},{ }^{\circ} R$} \\
\hline 450 & 0.96 & 446.2 & 447.9 & 448.6 & 448.9 & 449.1 \\
\hline $\begin{array}{l}470 \\
490\end{array}$ & & $\begin{array}{l}463.1 \\
480.8\end{array}$ & $\begin{array}{l}456.1 \\
484.7\end{array}$ & $\begin{array}{l}467.3 \\
486.3\end{array}$ & 467.9 & 468.3 \\
\hline 510 & & 499.4 & 503.8 & 505.6 & 506.6 & 507.3 \\
\hline 530 & $\checkmark$ & 519.1 & 523.5 & 525.4 & 526.4 & 527.1 \\
\hline 450 & 0.94 & 446.5 & 448.1 & 448.7 & 449.0 & 449.2 \\
\hline 470 & & 463.4 & 466.3 & 467.4 & 468.0 & 468.4 \\
\hline 490 & & 481.0 & 484.9 & 486.4 & 487.3 & 487.8 \\
\hline 510 & 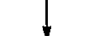 & 499.6 & 504.0 & 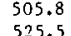 & 506.7 & 507.3 \\
\hline & & & & & & \\
\hline $\begin{array}{l}450 \\
470\end{array}$ & 0.90 & 447.1 & 448.4 & 448.9 & 449.2 & 449.3 \\
\hline 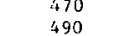 & & $\begin{array}{l}463.9 \\
481.5\end{array}$ & $\begin{array}{l}466.6 \\
485.2\end{array}$ & $\begin{array}{l}467.7 \\
486.7\end{array}$ & $\begin{array}{l}468.2 \\
487.4\end{array}$ & $\begin{array}{l}468.6 \\
487.9\end{array}$ \\
\hline 510 & & 500.0 & 504.3 & 506.0 & 506.9 & 507.5 \\
\hline 530 & + & 519.5 & 523.8 & 525.6 & 526.6 & 527.2 \\
\hline 450 & 0.80 & 448.7 & 449.3 & 449.5 & 449.7 & 449.7 \\
\hline 470 & & 465.4 & 467.5 & 468.3 & 468.7 & 468.9 \\
\hline $\begin{array}{l}490 \\
510\end{array}$ & & $\begin{array}{l}482.9 \\
501.9\end{array}$ & $\begin{array}{l}486.0 \\
505.0\end{array}$ & $\begin{array}{l}487.2 \\
506.5\end{array}$ & $\begin{array}{l}487.9 \\
507.3\end{array}$ & $\begin{array}{l}488.3 \\
507.8\end{array}$ \\
\hline $\begin{array}{l}510 \\
530\end{array}$ & $\downarrow$ & $\begin{array}{r}01.1 \\
520.3\end{array}$ & $\begin{array}{l}505.0 \\
524.4\end{array}$ & $\begin{array}{l}506.5 \\
526.1\end{array}$ & \begin{tabular}{|l|}
507.3 \\
527.0
\end{tabular} & $\begin{array}{l}507.8 \\
527.5\end{array}$ \\
\hline
\end{tabular}

(c) $\mathrm{R}=13.0 \mathrm{hr} \mathrm{ft}{ }^{2}{ }^{\circ} / \mathrm{Btu}$

\begin{tabular}{|c|c|c|c|c|c|c|}
\hline \multirow{3}{*}{$\begin{array}{c}\text { Amibent air } \\
\text { temperature, } \\
\mathrm{T}_{\mathrm{a}} \text {, } \\
{ }_{\mathrm{R}}\end{array}$} & \multirow{3}{*}{$\begin{array}{c}\text { Total } \\
\text { emittance } \\
\text { of roof } \\
\text { surface, } \\
\varepsilon_{\mathrm{r}} \\
\end{array}$} & \multicolumn{5}{|c|}{ Surface wind speed, $v$, mph } \\
\hline & & 0 & 5 & 10 & 15 & 20 \\
\hline & & \multicolumn{5}{|c|}{ Roof surface temperature, $T_{r},{ }^{\circ} R$} \\
\hline 450 & \multirow[t]{4}{*}{0.95} & 436.5 & 443.0 & 445.2 & 446.4 & 447.1 \\
\hline 470 & & 455.6 & 462.3 & 464.8 & 466.0 & 466.8 \\
\hline $\begin{array}{r}490 \\
510\end{array}$ & & $\begin{array}{l}475.4 \\
496.1\end{array}$ & 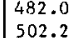 & $\begin{array}{l}484.5 \\
504.6\end{array}$ & $\begin{array}{l}485.8 \\
505.8\end{array}-10$ & $\mid \begin{array}{l}486.6 \\
506.6\end{array}-10$ \\
\hline & & 517.7 & 522.9 & 525.0 & 526.2 & 526.9 \\
\hline 450 & \multirow{4}{*}{0.94} & 436.8 & 443.1 & 445.4 & 446.5 & 447.2 \\
\hline & & 455.9 & 462.5 & 464.9 & 466.1 & 466.9 \\
\hline 490 & & 475.7 & 482.2 & 484.6 & 485.9 & 486.7 \\
\hline $\begin{array}{l}510 \\
530\end{array}$ & & 496.3 & 502.4 & 504.7 & 505.9 & 506.7 \\
\hline & \multirow{4}{*}{0.90} & & & & & \\
\hline 470 & & 456.4 & $\begin{array}{l}44.3 \\
462.8\end{array}$ & 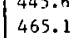 & $\begin{array}{l}446.1 \\
466.3\end{array}$ & 467.0 \\
\hline 490 & & 476.1 & 482.5 & 484.9 & 486.1 & 486.8 \\
\hline $\begin{array}{l}5100 \\
530\end{array}$ & & $\begin{array}{l}496.7 \\
518.1\end{array}$ & $\begin{array}{l}502.6 \\
523.3\end{array}$ & $\begin{array}{l}504.9 \\
525.3\end{array}$ & $\begin{array}{l}506.1 \\
526.4\end{array}$ & 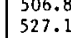 \\
\hline 450 & \multirow{4}{*}{0.80} & 438.8 & & 446.2 & 447.1 & 447.7 \\
\hline 470 & & 457.7 & 463.4 & 465.7 & 466.8 & 467.4 \\
\hline & & 477.3 & 483.3 & 485.4 & 486.5 & 487.2 \\
\hline 510 & & 497.7 & 503.3 & 505.4 & 506.5 & 507.2 \\
\hline & & & & & & \\
\hline
\end{tabular}

(b) $\mathrm{R}=8.0 \mathrm{hr} \mathrm{ft}^{2}{ }^{\circ} \mathrm{R} / \mathrm{Btu}$

\begin{tabular}{|c|c|c|c|c|c|c|}
\hline \multirow{3}{*}{$\begin{array}{c}\text { Ambient air } \\
\text { temperature, } \\
\mathrm{T}_{\mathbf{a}}, \\
{ }^{\mathrm{a}} \text {, }\end{array}$} & \multirow{3}{*}{$\begin{array}{c}\text { Total } \\
\text { emittance } \\
\text { of roof } \\
\text { surface, } \\
E_{\mathrm{r}} \\
\end{array}$} & \multicolumn{5}{|c|}{ Surface wind speed, $v$, mph } \\
\hline & & 0 & 5 & 10 & 15 & 20 \\
\hline & & \multicolumn{5}{|c|}{ Roof surface temperature, $T_{r},{ }^{\circ} R$} \\
\hline 450 & 0.96 & 439.5 & 444.4 & 446.2 & 447.1 & 447.7 \\
\hline 470 & & & 463.4 & & & 467.2 \\
\hline 490 & & & 482.8 & 485.0 & 486.2 & 486.9 \\
\hline & & 497.1 & 502.7 & 504.9 & & 506.8 \\
\hline & & 318.1 & 523.1 & 525.1 & 526.2 & 326.9 \\
\hline 450 & 0.94 & & 444.6 & 446.3 & 447.2 & 447.7 \\
\hline & & & 463.6 & & 466.6 & 467.3 \\
\hline 510 & & & 502.8 & & & $\begin{array}{l}480.0 \\
506.9\end{array}$ \\
\hline 530 & & 518.2 & 523.2 & 525.2 & 526.3 & 527.0 \\
\hline 450 & 0.90 & 440.3 & 444.9 & 446.5 & 447.4 & 447.9 \\
\hline 470 & 0.90 & & 463.9 & & & 467.4 \\
\hline & & & 483.3 & & & 487.1 \\
\hline $\begin{array}{l}510 \\
530\end{array}$ & & & $\begin{array}{l}503.1 \\
523.4\end{array}$ & & 506.3 & $\begin{array}{l}507.0 \\
5.27 .1\end{array}$ \\
\hline & & & & & & \\
\hline $\begin{array}{l}450 \\
470\end{array}$ & 0.80 & $\begin{array}{l}441.8 \\
460.1\end{array}-100$ & $\begin{array}{l}445.8 \\
464.8\end{array}-100$ & $\begin{array}{l}447.1 \\
466.4\end{array}$ & $\begin{array}{l}447.8 \\
467.3\end{array}$ & $\begin{array}{l}448.3 \\
467.8\end{array}$ \\
\hline & & & & & & 487.5 \\
\hline 510 & & & 503.8 & 505.7 & 506.7 & 507.4 \\
\hline 530 & & 519.3 & 524.0 & 525.8 & 526.8 & 527.4 \\
\hline
\end{tabular}

(d) $\mathrm{R}=20.0 \mathrm{hr} \mathrm{ft}^{2}{ }^{\circ} \mathrm{R} / \mathrm{Btu}$

\begin{tabular}{|c|c|c|c|c|c|c|}
\hline \multirow{3}{*}{$\begin{array}{l}\text { Ambient air } \\
\text { temperature, } \\
\mathrm{T}_{\mathrm{O}_{\mathrm{R}}},\end{array}$} & \multirow{3}{*}{$\begin{array}{c}\text { Total } \\
\text { emittance } \\
\text { of roof } \\
\text { surface, } \\
\varepsilon_{r} \\
\end{array}$} & \multicolumn{5}{|c|}{ Surface wind speed, $v$, mph } \\
\hline & & 0 & 5 & 10 & 15 & 20 \\
\hline & & \multicolumn{5}{|c|}{ Roof surface temperature, $r_{r},{ }^{\circ} R$} \\
\hline $\begin{array}{l}450 \\
470 \\
490 \\
510 \\
530 \\
\end{array}$ & 0.96 & & $\begin{array}{l}442.2 \\
461.7 \\
481.6 \\
501.9 \\
522.8 \\
\end{array}$ & \begin{tabular}{|l|}
444.7 \\
464.3 \\
484.2 \\
504.4 \\
525.0 \\
\end{tabular} & \begin{tabular}{|l|}
446.0 \\
456.7 \\
485.6 \\
550.7 \\
526.1 \\
\end{tabular} & $\begin{array}{l}446.8 \\
466.5 \\
486.4 \\
50.5 \\
526.9 \\
\end{array}$ \\
\hline & & & & $\begin{array}{l}444.8 \\
464.5 \\
484.3 \\
504.5 \\
525.1\end{array}$ & & $\begin{array}{l}446.9 \\
466.6 \\
486.5 \\
505.6 \\
526.9\end{array}$ \\
\hline $\begin{array}{l}450 \\
470 \\
490 \\
510 \\
530\end{array}$ & 0.90 & $\begin{array}{l}435.6 \\
455.0 \\
475.2 \\
496.1 \\
517.9\end{array}$ & \begin{tabular}{|l|}
442.5 \\
462.2 \\
482.0 \\
502.4 \\
523.2 \\
\end{tabular} & $\begin{array}{l}445.0 \\
464.7 \\
484.6 \\
504.7 \\
525.5 \\
\end{array}$ & \begin{tabular}{|l|}
446.3 \\
466.0 \\
485.9 \\
506.0 \\
526.3 \\
\end{tabular} & $\begin{array}{l}447.0 \\
466.8 \\
486.7 \\
506.7 \\
527.0\end{array}$ \\
\hline $\begin{array}{l}450 \\
470 \\
490 \\
510 \\
530\end{array}$ & 0.80 & $\begin{array}{l}437.1 \\
456.4 \\
476.4 \\
497.1 \\
518.6\end{array}$ & & & & $\begin{array}{l}447.4 \\
467.1 \\
487.0 \\
507.1 \\
527.3\end{array}$ \\
\hline
\end{tabular}


TABLE II. - CALORIMETRIC SKY TEMPERATURE

AND SPECTRAL SKY FLUX

\begin{tabular}{|c|c|c|}
\hline $\begin{array}{l}\text { Ambient air } \\
\text { temperature, } \\
\mathrm{T}_{\mathrm{a}}, \\
{ }_{\mathrm{O}}\end{array}$ & $\begin{array}{c}\text { Calorimetric sky } \\
\text { temperature, } \\
{ }_{\mathrm{T}_{\mathrm{R}}},\end{array}$ & $\begin{array}{l}\text { Spectral sky } \\
\text { flux, } \\
\text { q's, } \\
\text { Btu/hr ft }{ }^{2}\end{array}$ \\
\hline $\begin{array}{l}450 \\
470 \\
490 \\
510 \\
530\end{array}$ & $\begin{array}{l}393.3 \\
419.8 \\
446.9 \\
474.5 \\
502.7\end{array}$ & $\begin{array}{r}3.78 \\
6.97 \\
11.33 \\
16.76 \\
24.7\end{array}$ \\
\hline
\end{tabular}

${ }^{a}$ Ref. 7.

bRef. 12 for a relative humidity of 60 percent.

TABLE III. - TYPICAL EMITTANCES

\begin{tabular}{|c|c|c|c|}
\hline & $\begin{array}{c}\text { Wavelength band, } \\
\mu m\end{array}$ & Emittance & Reference \\
\hline \multicolumn{4}{|c|}{ Roofing materials } \\
\hline $\begin{array}{l}\text { Asphalt shingles } \\
\text { Builtup roofs } \\
\text { Gravel (0.5-cm rocks) } \\
\text { Roofing paper } \\
\text { Tar paper } \\
\text { Coal tar pitch } \\
\text { Asphalt shingles }\end{array}$ & $\begin{array}{l}5-25 \\
5-25 \\
8-12 \\
---- \\
---- \\
8-12 \\
8-14\end{array}$ & $\begin{array}{l}0.94 \\
.95 \\
.96 \\
.91 \\
.93 \\
.89 \\
.92 \\
\end{array}$ & $\begin{array}{l}\text { NASA measurements } \\
\text { NASA measurements } \\
15 \\
18 \\
18 \\
19 \\
20\end{array}$ \\
\hline \multicolumn{4}{|c|}{ Terrain materials } \\
\hline $\begin{array}{l}\text { Asphalt } \\
\text { Asphalt paving } \\
\text { Concrete } \\
\text { Concrete walk } \\
\text { Concrete (rough) } \\
\text { Sand (fine grains, dry) } \\
\text { Sand (fine grains, very wet) } \\
\text { Soil, dry } \\
\text { Soil, wet } \\
\text { Thick green grass }\end{array}$ & $\begin{array}{l}9-12 \\
8-12 \\
8-12 \\
9-12 \\
8-12 \\
---- \\
9-12 \\
9-12 \\
---- \\
---- \\
9-12\end{array}$ & $\begin{array}{l}0.92 \\
.91 \\
.96 \\
.92 \\
.97 \\
.94 \\
.95 \\
.96 \\
.92 \\
.95 \\
.99\end{array}$ & $\begin{array}{l}21 \\
19 \\
15 \\
21 \\
15 \\
18 \\
22 \\
22 \\
23 \\
23 \\
22\end{array}$ \\
\hline
\end{tabular}




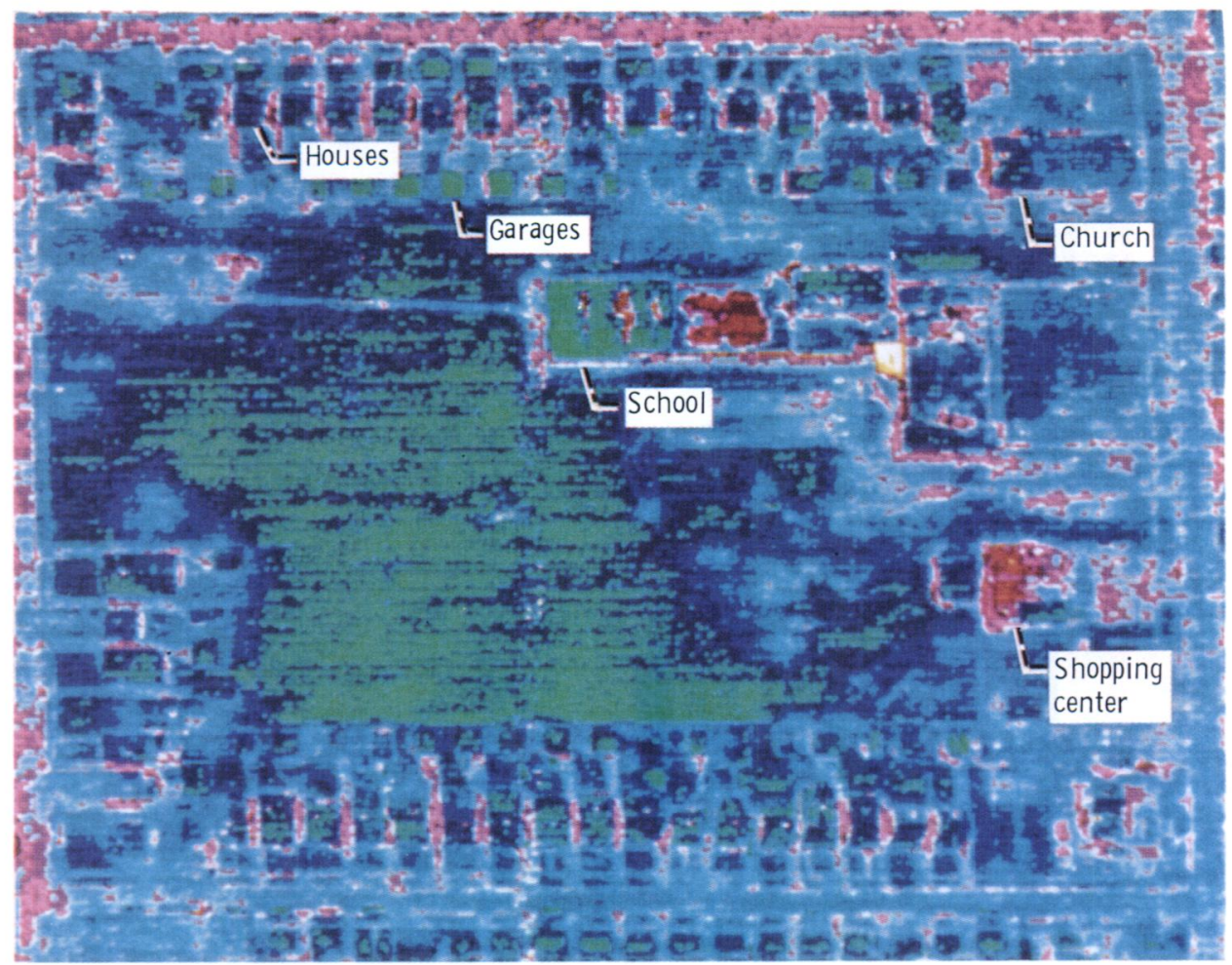

(a) High surface wind speed.

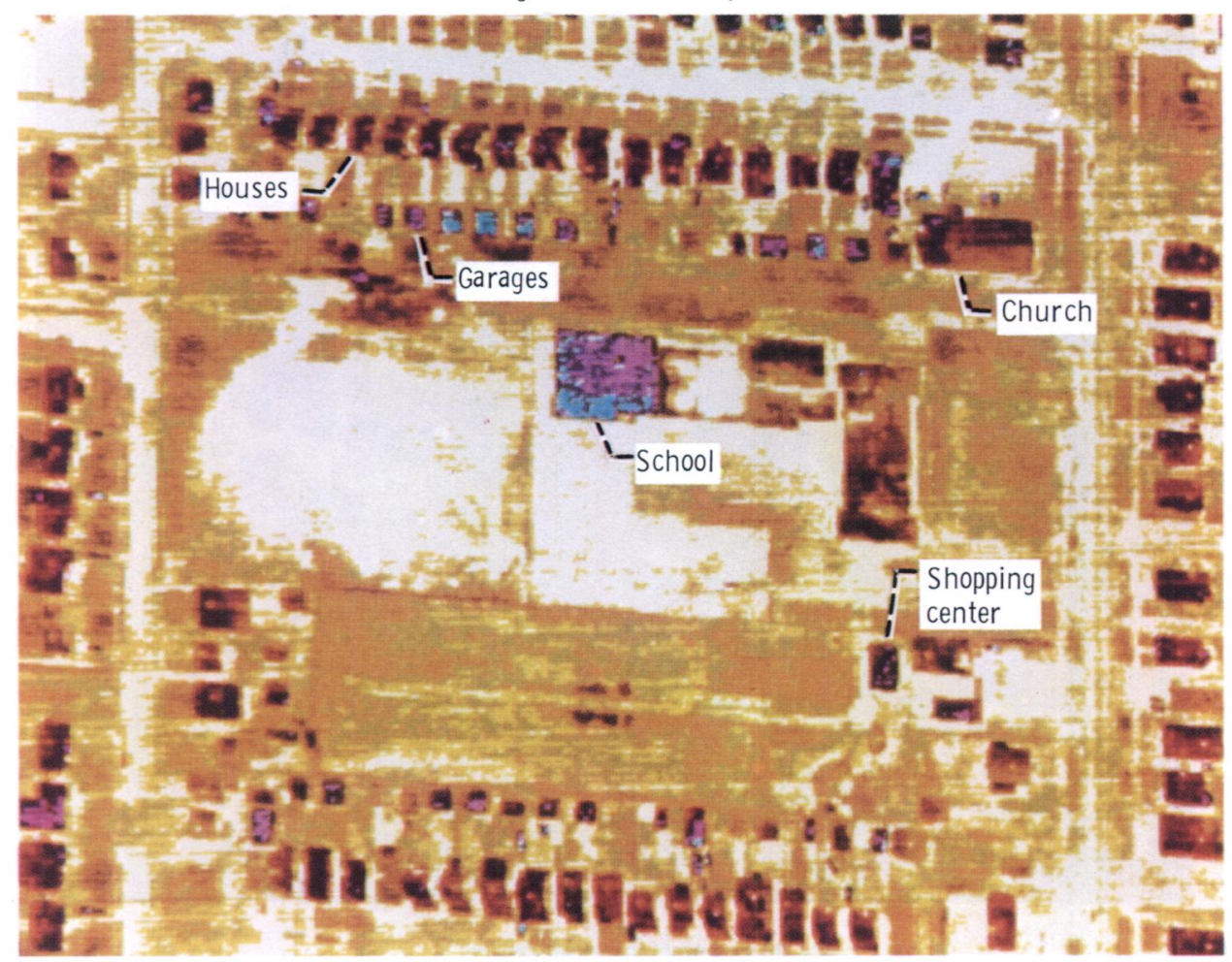

(b) Low surface wind speed.

Figure 1. - Effect of surface wind speed on aerial thermography. 


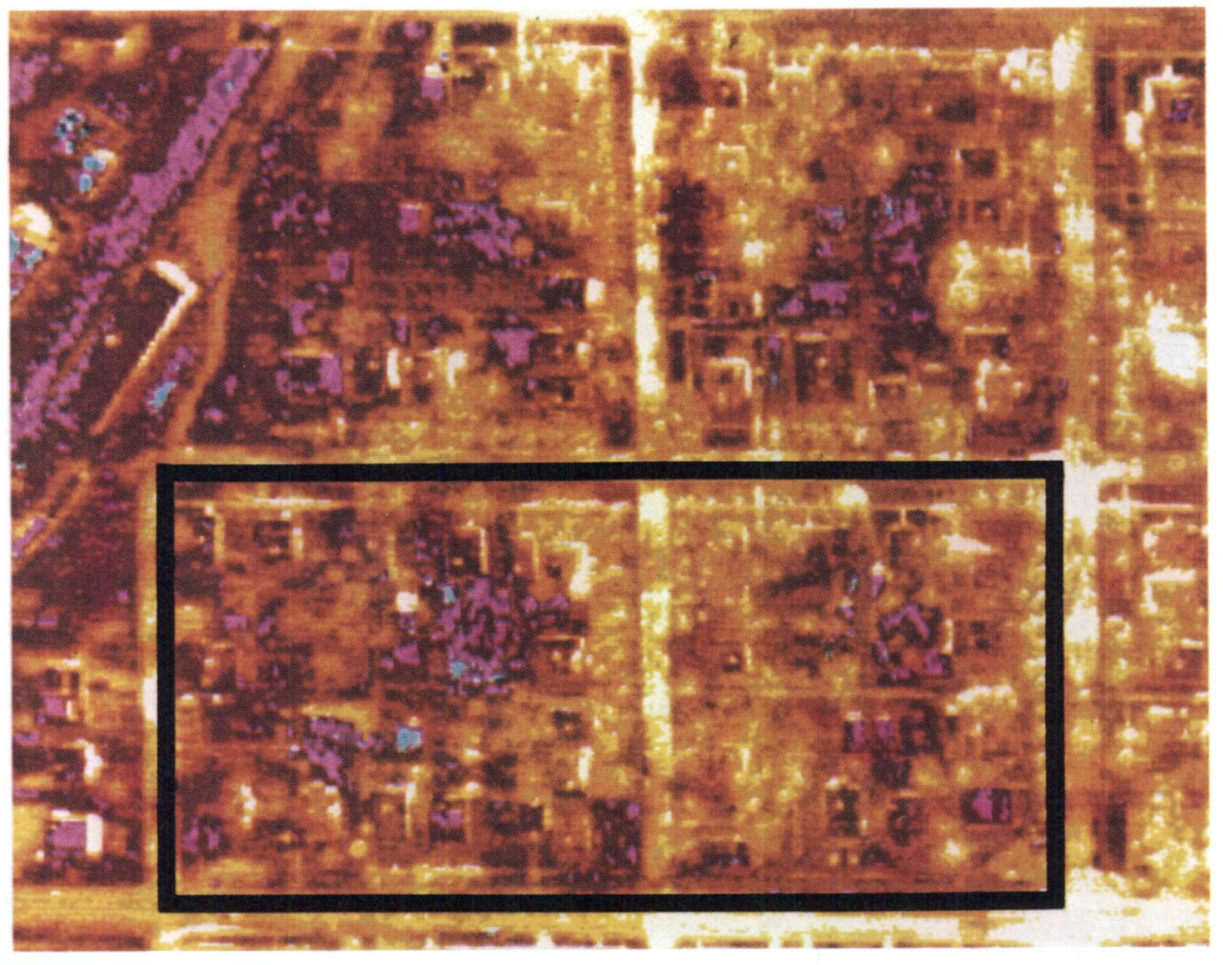

(a) High ambient temperature.

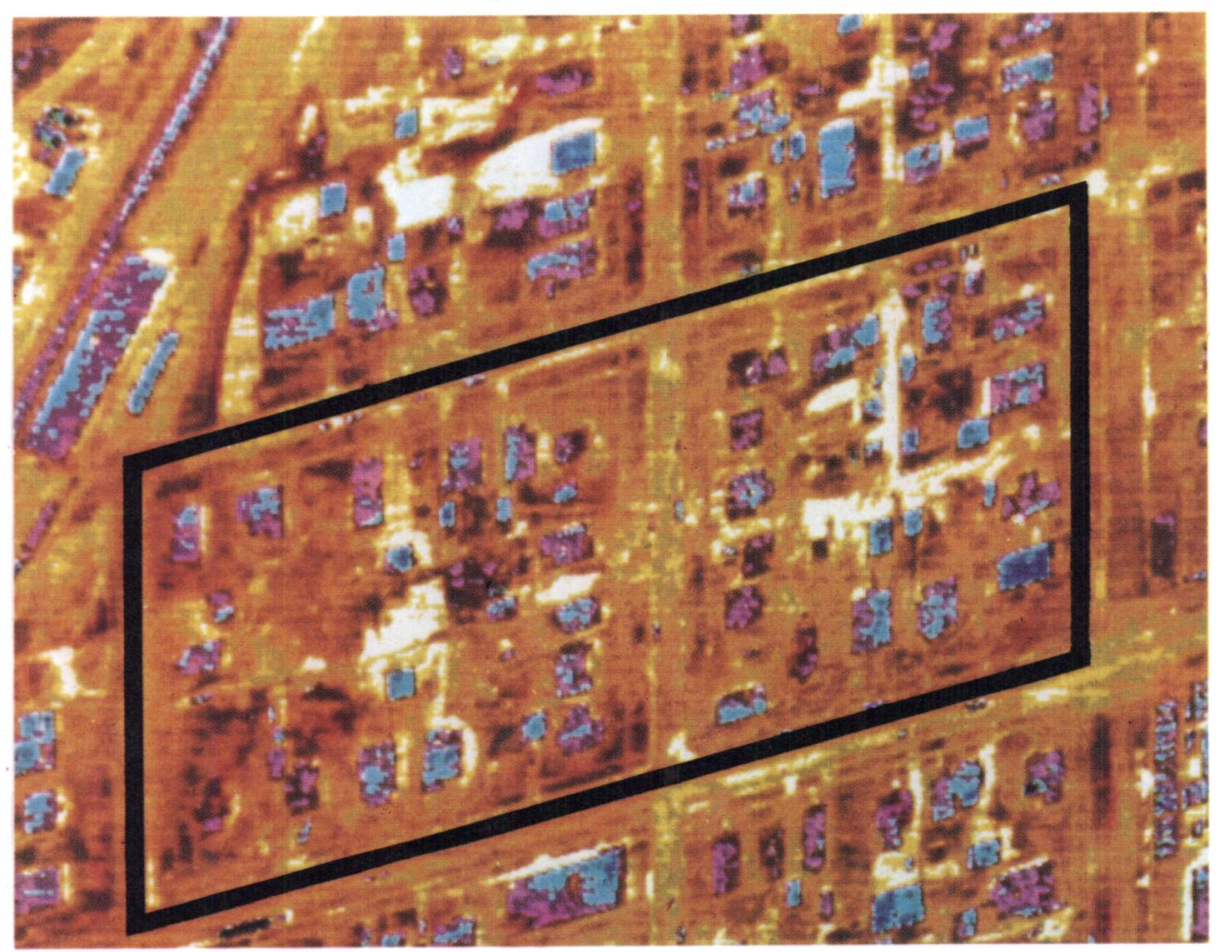

(b) Low a mbient temperature.

Figure 2. - Effect of ambient air temperature on aerial thermography. 
Sky temperature $\mathrm{T}_{\mathrm{S}}$

Ambient air temperature $T_{a}$

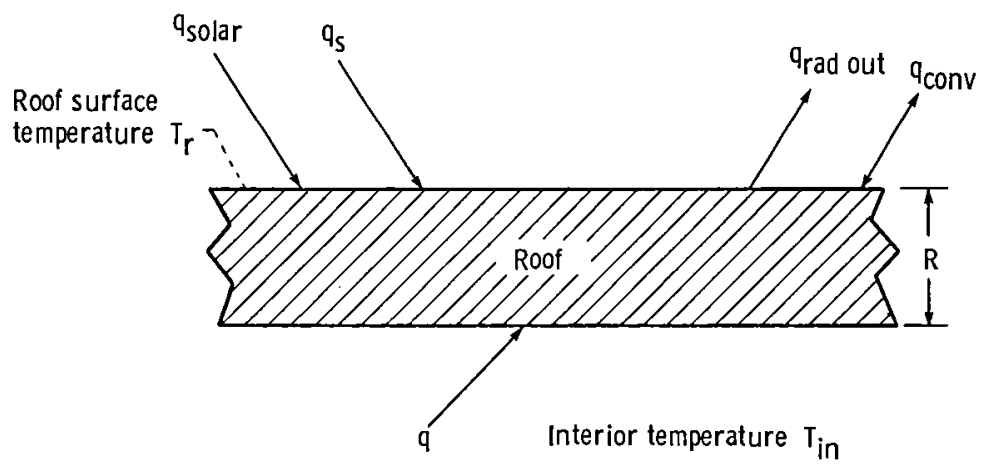

Figure 3. - Rooftop heat transfer model, where q represents the various energy sources, $T$ represents the associated temperatures, and $R$ represents roof thermal resistance.

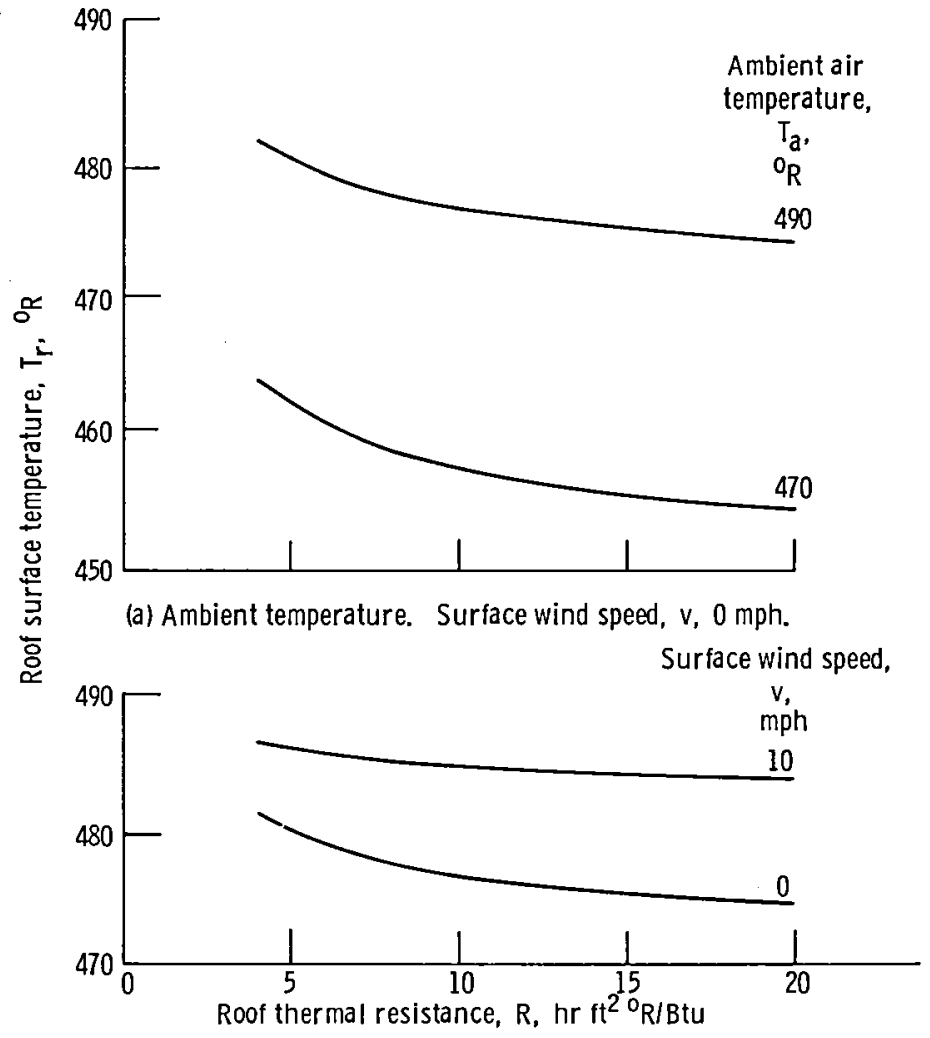

(b) Wind speed. Ambient air temperature, $\mathrm{T}_{\mathrm{a}}, 490^{\circ} \mathrm{R}$.

Figure 4. - Typical variation of roof surface temperature with roof thermal resistance. Total emittance of roof surface, $\varepsilon_{\mathrm{r}}, 0.90$. 


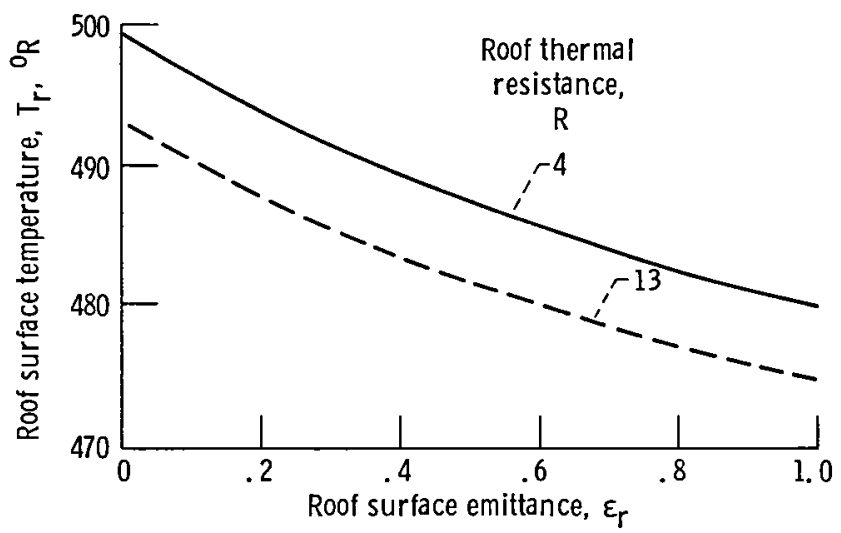

Figure 5. - Typical variation of roof surface temperature with roof surface emittance. Surface wind speed, $v$, $0 \mathrm{mph}$; ambient air temperature, $\mathrm{T}_{\mathrm{a}}, 490^{\circ} \mathrm{R}$.

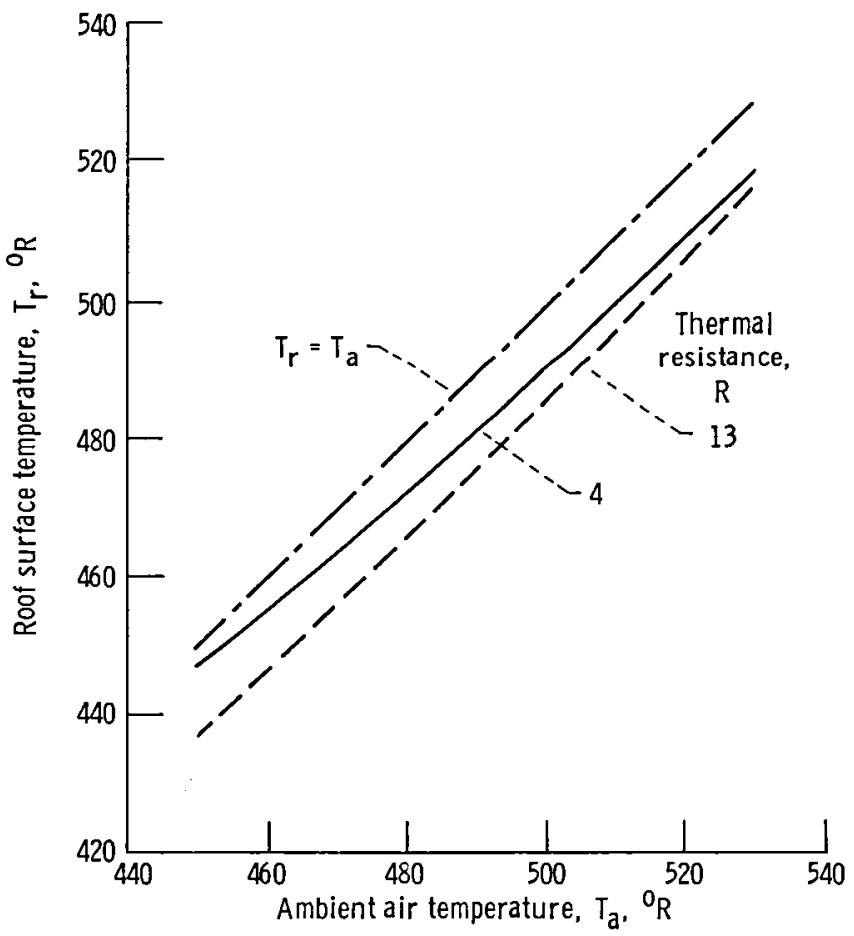

Figure 6. - Typical variation of roof surface temperature with ambient air temperature. Surface wind speed, v, $0 \mathrm{mph}$; total emittance of roof surface, $\varepsilon_{r}, 0.90$. 


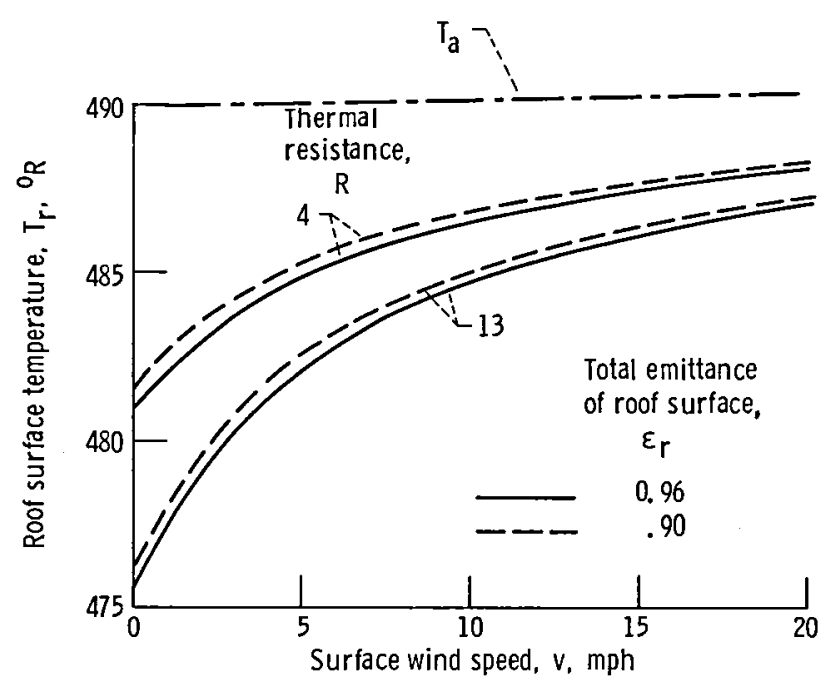

Figure 7. - Typical variation of roof surface temperature with surface wind speed.

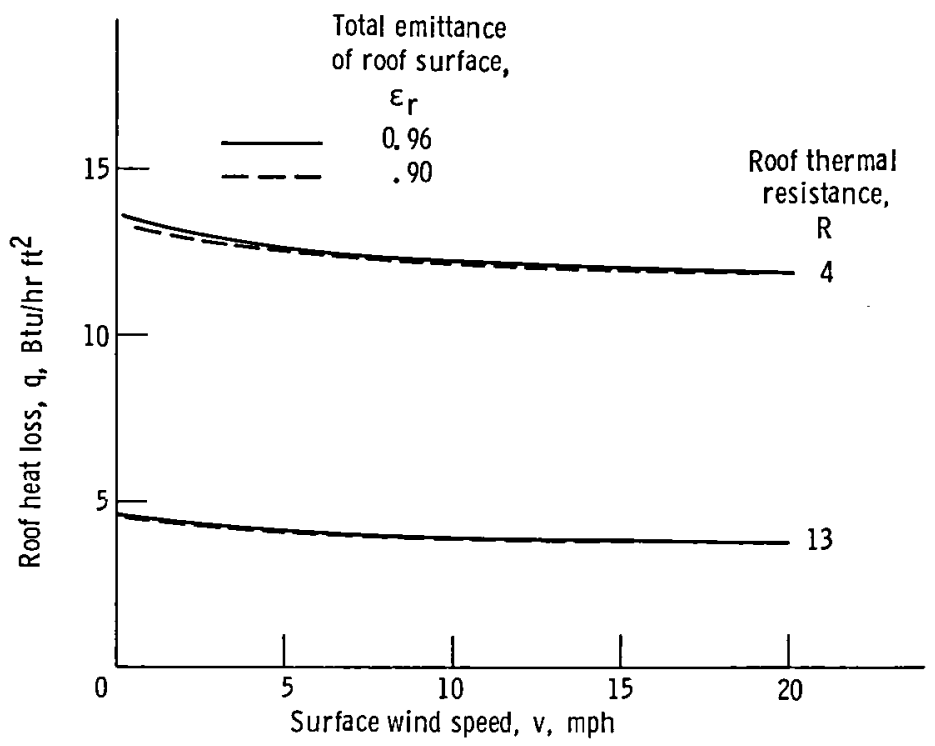

Figure 8. - Typical variation of roof heat loss with surface wind speed. Ambient air temperature, $\mathrm{T}_{\mathrm{a}}, 490^{\circ} \mathrm{R}$. 


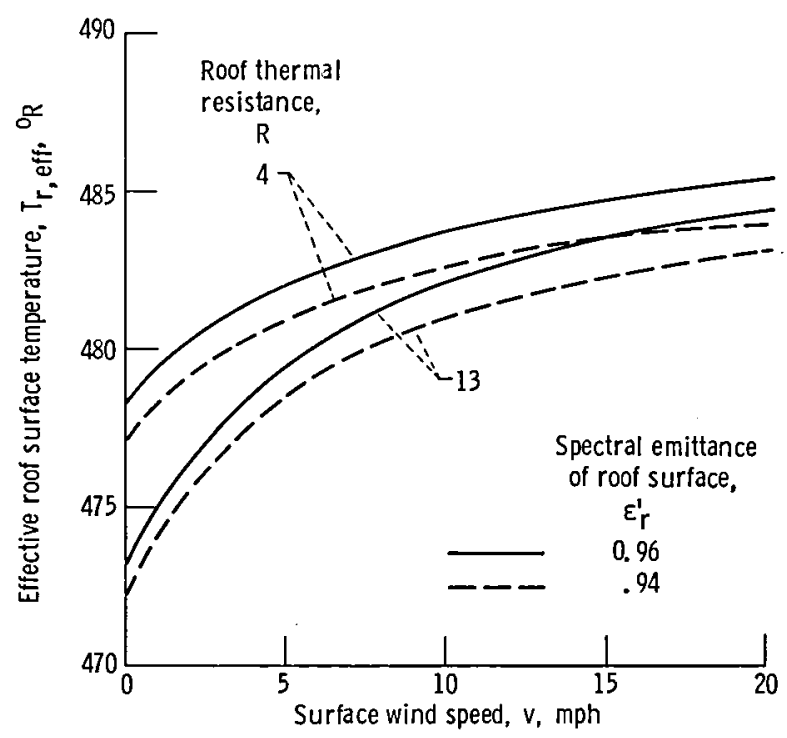

Figure 9. - Typical variation of effective roof surface temperature with surface wind speed. Ambient air temperature, $\mathrm{T}_{\mathrm{a}} \cdot 490^{\circ} \mathrm{R}$.

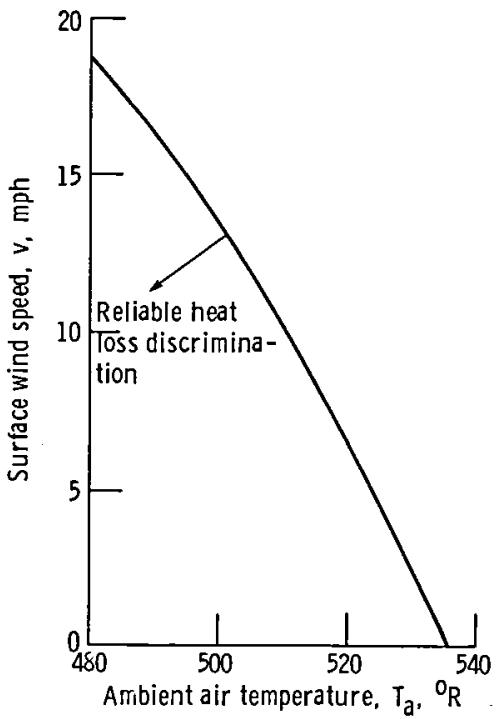

Figure 10. - Heat loss discrimination for clear skies. $0.94 \leq \varepsilon_{r}^{\prime} \leq 0.96$. 


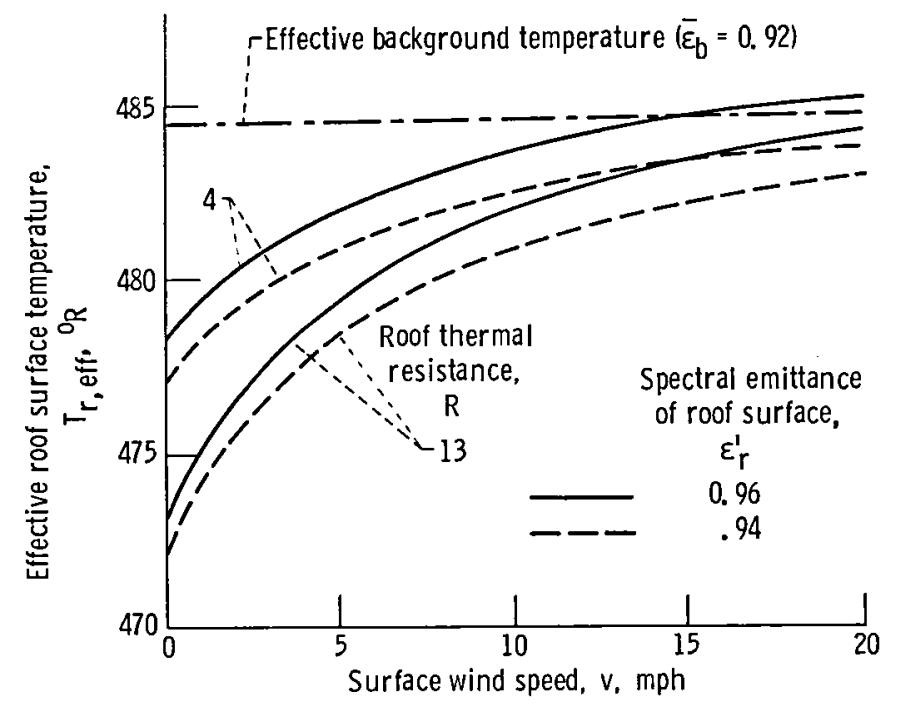

Figure 11. - Typical variation of effective roof surface temperature with surface wind speed. Ambient air temperature, $\mathrm{T}_{\mathrm{a}}, 490^{\circ} \mathrm{R}$.

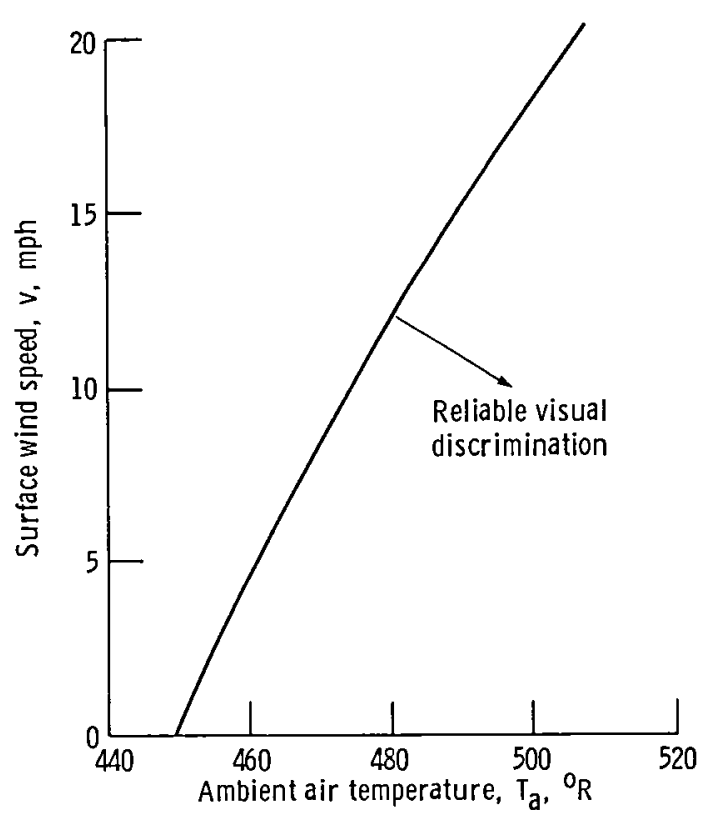

Figure 12. - Visual discrimination for clear skies. Average spectral (8 to $14 \mu \mathrm{m}$ ) background emittance, $\bar{\varepsilon}_{\mathrm{b}} \geq 0.92$; spectral emittance of roof surface, $\varepsilon_{r}^{\prime} \leq 0 . \%$. 


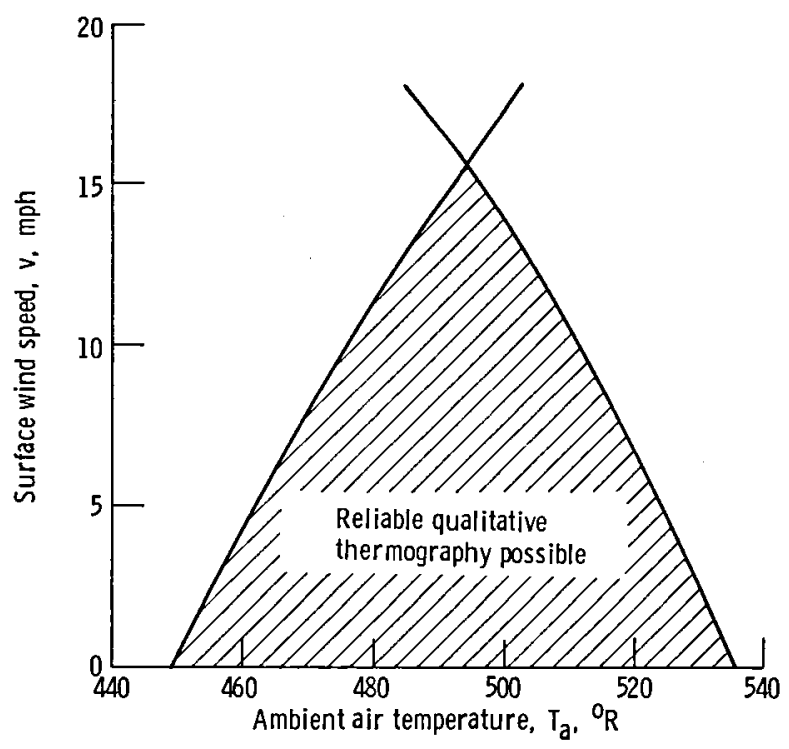

Figure 13. - Complete discrimination for clear skies.

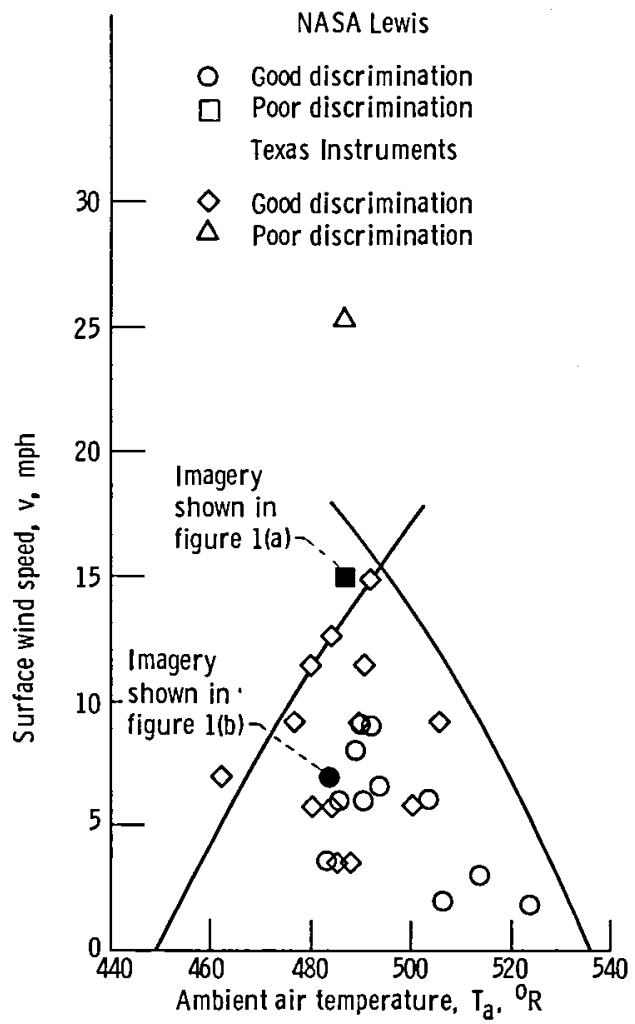

Figure 14. - Comparison of analytical operational map with experimental thermography. 


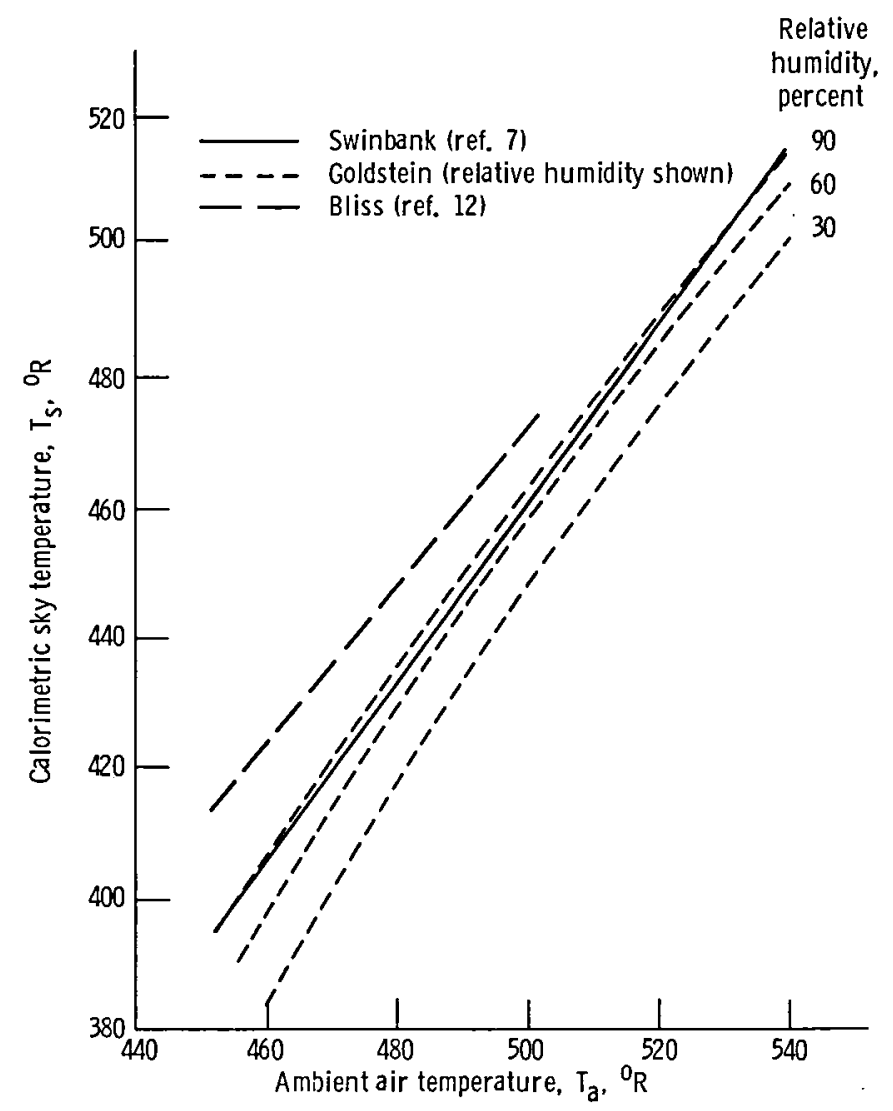

Figure 15. - Calorimetric (total) sky temperature.

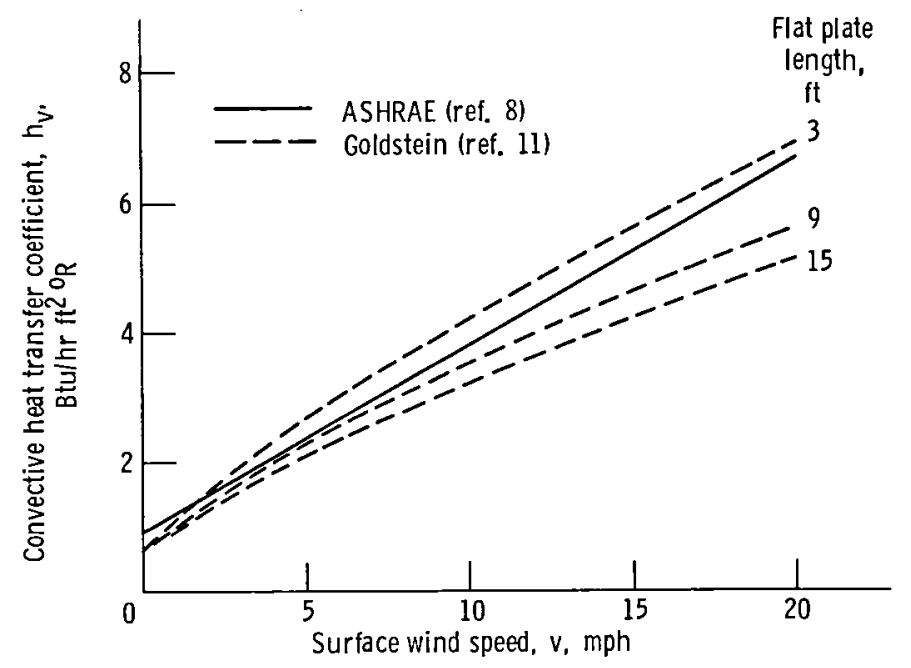

Figure 16. - Convective heat transfer coefficient. 


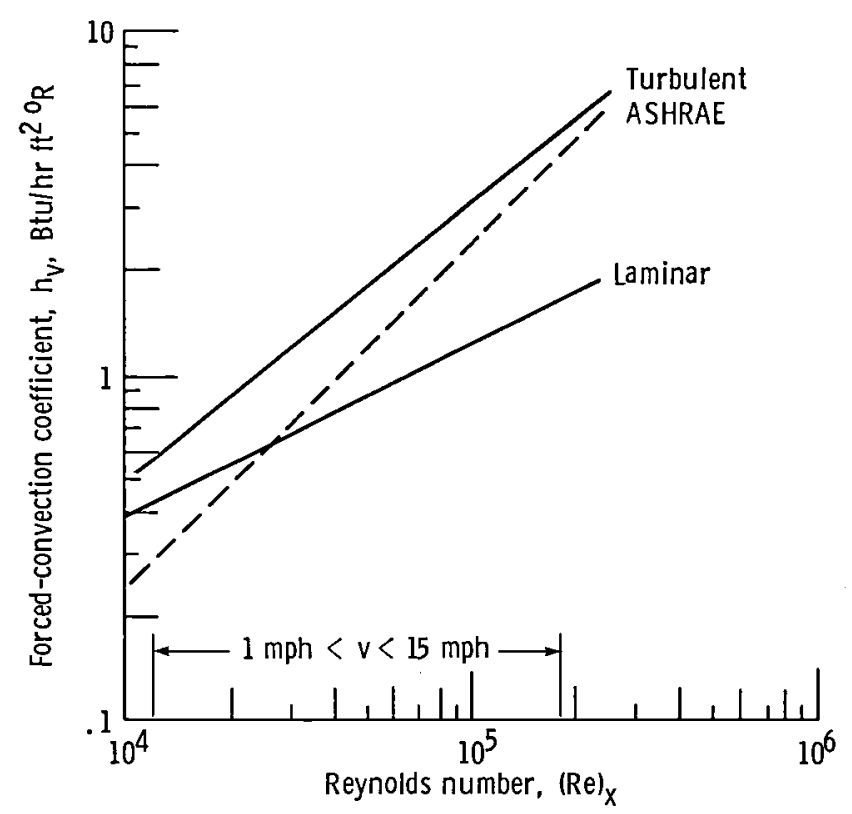

Figure 17. - Comparison of convection coefficient predictions for 1-foot-square plate.

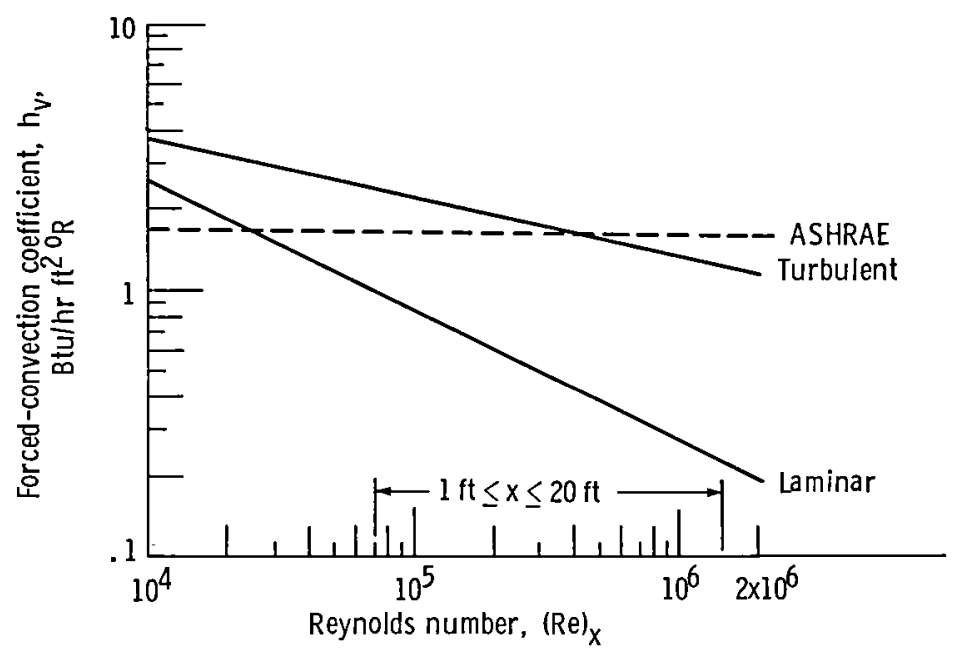

Figure 18. - Comparison of convection coefficient predictions for constant surface wind speed of $6 \mathrm{mph}$. 


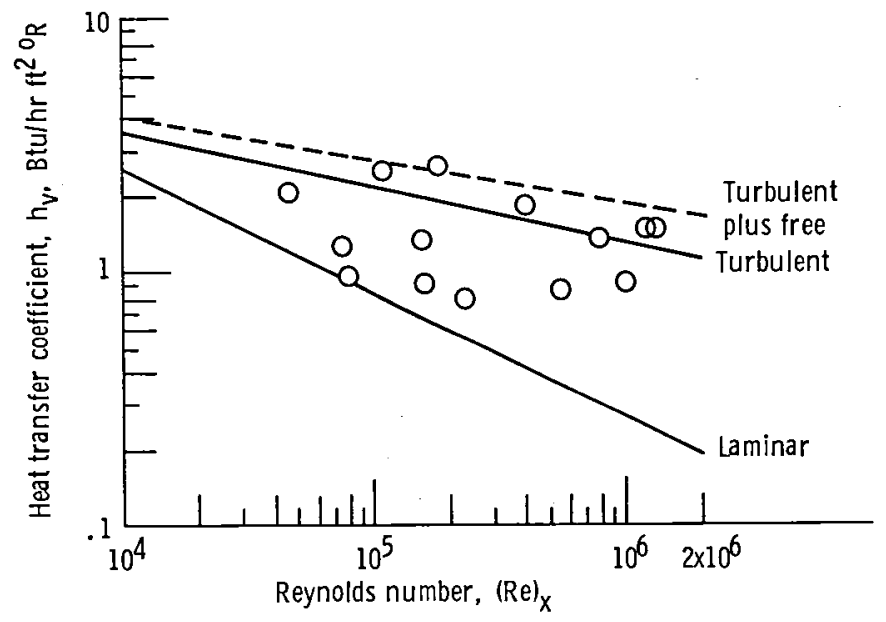

Figure 19. - Comparison of experimental convection coefficients with analytical predictions. Surface wind speed, $v$, $6 \mathrm{mph}$. 


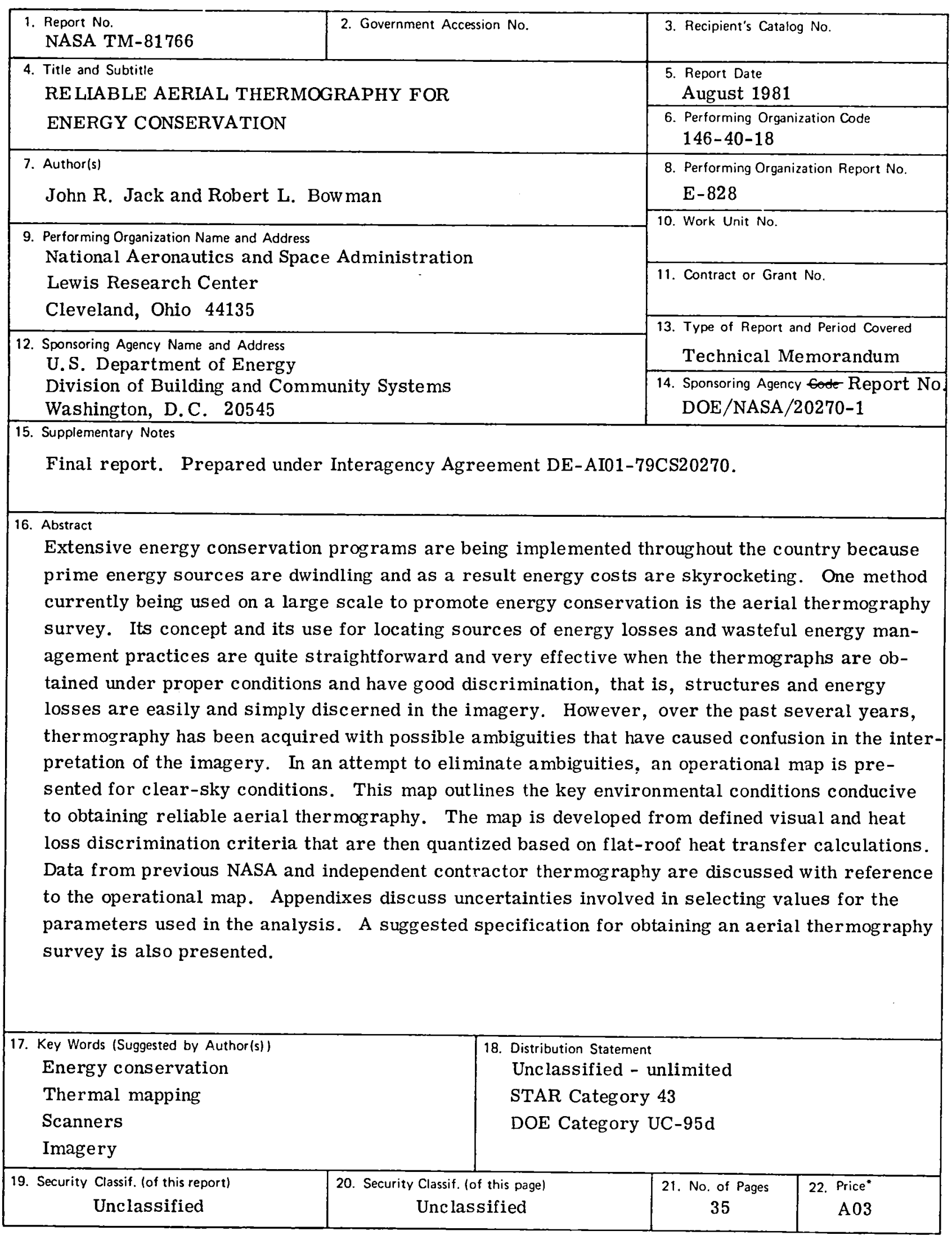

* For sale by the National Technical Information Service, Springfield, Virginia 22161 


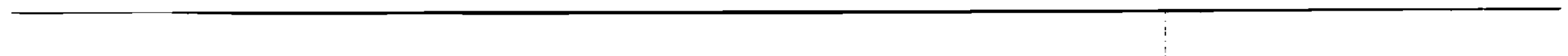


National Aeronautics and

Space Administration

Washington, D.C.

20546

Official Business

Penalty for Private Use, $\$ 300$
Postage and Fees Paid National Aeronautics and

Space Administration

NASA-451 